\title{
Surface Morphology of Comets and Associated Evolutionary Processes: A Review of Rosetta's Observations of 67P/Churyumov-Gerasimenko
}

\author{
M.R. El-Maarry ${ }^{1}$ - O. Groussin ${ }^{2}$ - H.U. Keller ${ }^{3}$.

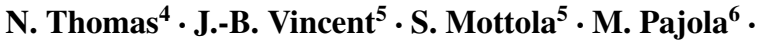 \\ K. Otto ${ }^{5}$ - C. Herny ${ }^{4}$ S. Krasilnikov ${ }^{7,8}$
}

Received: 19 November 2018 / Accepted: 21 May 2019 / Published online: 12 June 2019

(C) The Author(s) 2019

\begin{abstract}
Comets can be regarded as active planetary bodies because they display evidence for nearly all fundamental geological processes, which include impact cratering, tectonism, and erosion. Comets also display sublimation-driven outgassing, which is comparable to volcanism on larger planetary bodies in that it provides a conduit for delivering materials from the interior to the surface. However, in the domain of active geological bodies, comets occupy a special niche since their geologic activity is almost exclusively driven by externally supplied energy (i.e. solar energy) as opposed to an internal heat source, which makes them "seasonally-active" geological bodies. During their active phase approaching the Sun, comets also develop a transient atmosphere that interacts with the surface and contributes to its evolution, particularly by transporting materials across the surface. Variations in solar energy input on diurnal and seasonal scale cause buildup of thermal stresses within consolidated materials that lead to weathering through fracturing, and eventually mass-wasting. The commonly irregular shapes of comets also play a major role in their evolution by leading to (1) non-uniform gravitational forces that affect material movement across the surface, and
\end{abstract}

Post 67P/Churyumov-Gerasimenko Perspectives

Edited by Nicolas Thomas, Björn Davidsson, Laurent Jorda, Ekkehard Kührt, Raphael Marschall, Colin Snodgrass and Rafael Rodrigo

M.R. El-Maarry

m.elmaarry@bbk.ac.uk

1 Birkbeck College, University of London, WC1E 7HX, London, UK

2 Aix Marseille Univ., CNRS, CNES, LAM, Marseille, France

3 Institut für Geophysik und extraterrestrische Physik (IGEP), Technische Universität Braunschweig, 38106 Braunschweig, Germany

4 Physikalisches Institut, University of Bern, Sidlerstr. 5, 3012 Bern, Switzerland

5 Deutsches Zentrum für Luft- und Raumfahrt (DLR), Institut für Planetenforschung, 12489 Berlin, Germany

6 INAF Osservatorio Astronomico di Padova, Vicolo dell'Osservatorio 5, 35122 Padova, Italy

7 Vernadsky Institute of Geochemistry and Analytical Chemistry RAS, 119334 Moscow, Russia

8 Max-Planck-Institut für Sonnensystemforschung, 37077 Göttingen, Germany 
(2) spatially heterogeneous outgassing patterns that affect the comet's orbital dynamics and lead to tidal stresses that can further fracture the nucleus. In this chapter, we review the surface morphology of comet 67P/Churyumov-Gerasimenko as well as its seasonal evolution as viewed by Rosetta from August 2014 to September 2016, their link to various processes, and the forces that drive surface evolution.

Keywords Comets · Geology · Rosetta $\cdot$ Surfaces · 67P, Churyumov-Gerasimenko · Geomorphology $\cdot$ Surface processes

\section{Introduction}

Previous flyby missions to comets had provided snapshots of morphologically diverse worlds that are home to unique geological processes. Close-up images of cometary nuclei are often challenging to interpret because comets offer an environment that is impossible to replicate in its entirety on any other planetary body. Comets combine a complex composition incorporating various forms of ice, dust, and organics, low density, high porosity, a microgravity environment, and transient activity to create a landscape that challenges comparative studies with other planetary bodies. Pre-Rosetta missions had flown by five different comets (Fig. 1) giving us remarkable insights into the diverse surface morphologies of cometary nuclei. These missions demonstrated that while all comets share common surface traits, they were also different from one another. While fly-by images from these diverse small bodies enabled theories to be developed about the processes controlling cometary activity and resurfacing, the Rosetta mission at Comet Churyumov-Gerasimenko was able to directly test these theories through longer-term reconnaissance of the surface.

The Giotto, Vega 1, and Vega 2 missions to comet Halley ${ }^{1}$ were the first missions to acquire resolved images of a comet's nucleus (Keller et al. 1986; Sagdeev et al. 1986). Images from the Giotto mission in particular indicated that only minor parts of the surface were active (Keller et al. 1986) and suggested a morphologically diverse and rough surface that displayed putative ridges, mountains, and depressions. Higher resolution (10 s of meters/pixel) images of Borrelly's surface from the Deep Space 1 mission were the first to show unambiguously the morphological diversity of cometary nuclei. Borrelly displayed mottled (rough) and smooth terrains, and sub parallel sets of ridges and fractures, but lacked clear evidence of impact craters, which suggested a young active surface (Soderblom et al. 2002). In 2004, the Stardust mission flew by comet Wild 2 and returned images that showed a surface predominantly composed of irregular and circular depressions with variable sizes reaching up to $2 \mathrm{~km}$ in width, along with pinnacles and limited signs of mass-wasting (Brownlee et al. 2004).

In 2005, the Deep Impact mission flew by Tempel 1 and returned images showing a similarly diverse surface, yet distinct from that of Borrelly (A'Hearn et al. 2005). Tempel 1 displayed circular and irregular depressions, smooth units that suggested a flow behavior, and for the first time, evidence of layering (A'Hearn et al. 2005; Thomas et al. 2007). The mission also included an impact experiment to study the ejected materials (A'Hearn et al. 2005). The Deep Impact spacecraft followed its mission at Tempel 1 with a flyby of comet Hartley 2 in 2010. Hartley 2 displayed rough knobby terrains along the margins of the bilobed-shaped nucleus and smooth terrains in the waist/neck region (Fig. 1). The nucleus lacked circular

\footnotetext{
${ }^{1}$ For brevity, and unless we state otherwise, we will refer to comets in this section by their common names.
} 


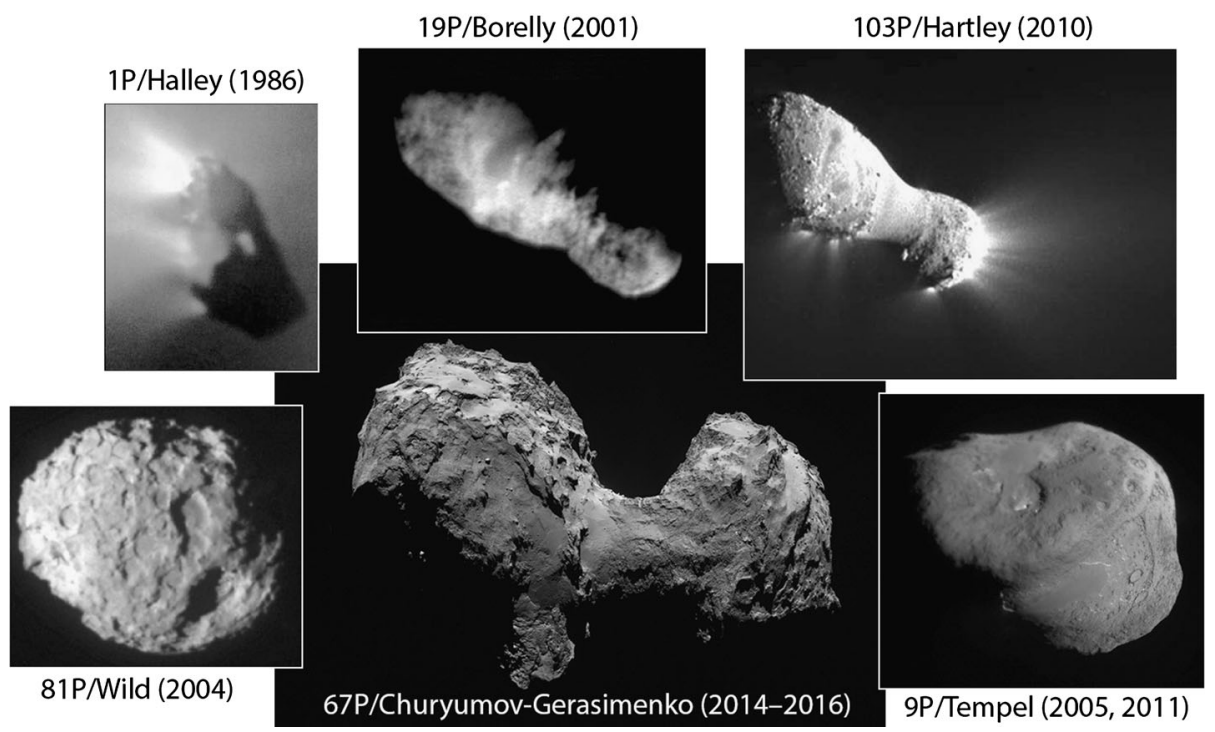

Fig. 1 All comets that have been visited by spacecraft (not to scale). Dates in parenthesis indicate the time when the comets were visited. 9P/Tempel is the only comet to be visited by two different spacecraft at different times. 67P/Churyumov-Gerasimenko is the only comet to be investigated by an orbiting spacecraft continuously for more than 2 years

features that dominate Wild 2's landscape and are scattered around on Tempel 1. In addition, no evidence for layering or flowing material was observed (A'Hearn et al. 2011; Thomas et al. 2013b). However, correlations between jet activity and features such as pits, arcuate depressions, scarps, and rimless depressions suggested that mass wasting contributes to volatile sublimation at active comets (Bruck Syal et al. 2013). Distribution of high and low-albedo blocks (where high-albedo blocks were theorized to be enriched in surficial volatiles) near scarps and areas of enhanced dust jets suggested a formation mechanism related to jet activity and mass wasting. Finally, the Stardust spacecraft followed its earlier flyby of Wild 2 with a second visit of Tempel 1. The second flyby in 2011 allowed the imaging and mapping of previously unobserved areas of the comet in 2005. The expanded view demonstrated that the smooth units were preferentially present in gravitational lows (Thomas et al. 2013a; Veverka et al. 2013). In addition, the repeated viewing of Tempel 1 over two perihelia meant that for the first time a study of surface changes could be carried out. The most notable change that was observed was a $\sim 50 \mathrm{~m}$ scarp retreat in one of the smooth units (Thomas et al. 2013a; Veverka et al. 2013).

The Rosetta mission to 67P/Churyumov-Gerasimenko (herein after referred to as 67P) expanded our view of cometary surfaces by offering us a near-continuous stream of data for more than two terrestrial years (from August 2014 to September 2016), which was highlighted by the first landing of a spacecraft (Philae) on the surface of a comet in November 2014, and perihelion passage in August 2015. During these two years, Rosetta spent a substantial amount of mission time orbiting $30 \mathrm{~km}$ away or less from 67P, which allowed the mission's main scientific camera, the Optical, Spectroscopic, and Infrared Remote Imaging 

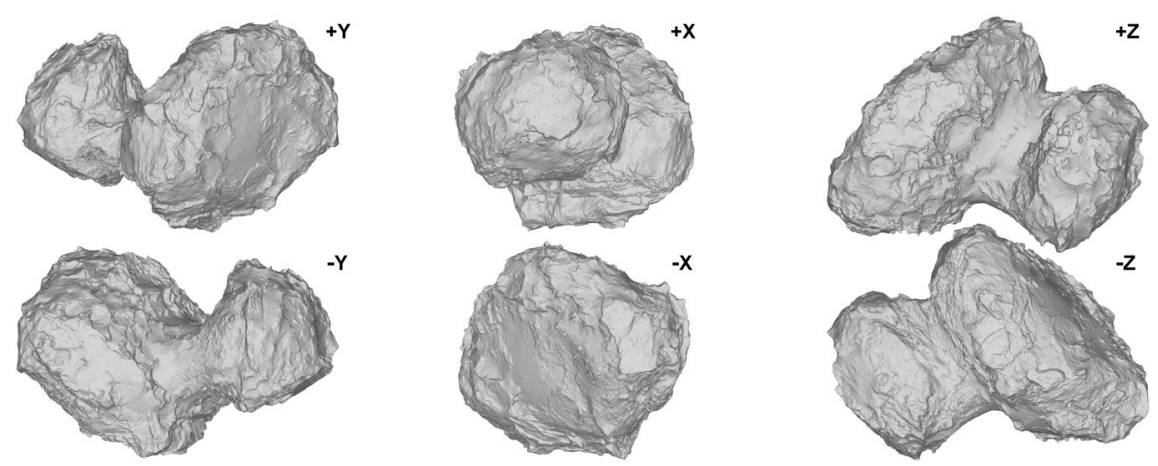

Fig. 2 Different viewpoints for the most recent shape model of comet 67P prepared with stereo-photogrammetry techniques. North is up for views along the $X$ and $Y$ axes. Views along the $Z$-axis are polar views $(+Z$ for the northern polar view, $-Z$ for the southern one). Figure from Preusker et al. (2017)

System (OSIRIS) (Keller et al. 2007), to image the surface at resolutions of $50 \mathrm{~cm} / \mathrm{pixel}$ or higher for most of the mission's lifetime. ${ }^{2}$

In the coming sections, we review the large body of work that was published using data from the Rosetta mission, particularly from OSIRIS, to showcase the various morphological elements that shape up the surface of 67P. Section 2 presents 67P's shape and large-scale morphology. Section 3 focuses on surface processes that affect the morphology on all scales. In Sect. 4, we summarise current hypotheses regarding the driving forces behind these active processes.

\section{67P's Morphology}

\subsection{Overall Shape, Volume and Density}

Comet 67P's nucleus has a bilobate shape (Fig. 2) with overall dimensions of approx. $4.3 \times 2.6 \times 2.1 \mathrm{~km}$ along its principle axes (Jorda et al. 2016). A larger lobe (approx. $4.1 \times 3.5 \times 1.6 \mathrm{~km}$ ) is connected to a smaller lobe (approx. $2.5 \times 2.1 \times 1.6 \mathrm{~km}$ ) by a narrow neck region that constitutes only $7 \%$ of the comet's total volume (Jorda et al. 2016). Early studies following Rosetta's arrival at comet 67P's vicinity (e.g., Preusker et al. 2015) reported only estimates of the comet's shape and volume since the southern hemisphere was not illuminated at the time (i.e. prior to May 2015). Following equinox in May 2015, these earlier estimates were refined to the values reported by Jorda et al. (2016) based on full shape models derived through stereo-photoclinometry methods. Preusker et al. (2017) used stereo-photogrammetric analysis to derive more accurate estimates of the total volume $\left(18.56 \mathrm{~km}^{3} \pm 0: 02 \mathrm{~km}^{3}\right)$, as well as mean density $\left(537.8 \mathrm{~kg} / \mathrm{m}^{3} \pm 0.7 \mathrm{~kg} / \mathrm{m}^{3}\right)$. The density estimate is based on calculated mass of approx. $9.98 \times 10^{12} \mathrm{~kg}$ as measured by the Radio Science Investigation experiment (Pätzold et al. 2016). In 2014, the comet had a spin period of approx. 12.404 hours. The spin period increased to 12.430 hours in May 2015 before dropping rapidly (i.e. the comet's rotation speed increased) to 12.305 hours in Aug. 2015 (Jorda et al. 2016). The changes in the spin period resulting from changes in torques

\footnotetext{
${ }^{2}$ Images were acquired at lower resolutions when Rosetta was moved further away from the comet during perihelion to protect the spacecraft, or during far excursions to study outer coma structures.
} 
caused by non-gravitational forces had an important role in driving some of the changes that affected the comet during the mission's lifetime (see Sect. 3).

\subsection{Large-Scale Morphology}

Images acquired from 67P reveal remarkably diverse surface morphologies and textures. This is possibly due to the higher spatial resolutions achieved by Rosetta's cameras than in most of these missions, and the longer duration and orbiting nature of the mission, which allowed for mapping of the entire nucleus. In terms of regional morphology, the principle terrains on 67P encompass exposed consolidated terrains, smooth plains, dust-covered units, and large-scale depressions (Thomas et al. 2015b, Fig. 3). The large morphological and structural boundaries between these terrain types delineate the identified geographic regions of the comet (Fig. 4, El-Maarry et al. 2015b, 2016; Thomas et al. 2015b, 2018).

Consolidated terrains are essentially the comet's exposed surface, which retain enough structural integrity to sustain fractures, cliffs, and overhangs (Fig. 3). The fragmentation of these consolidated materials results in mass wasting deposits and boulders of variable sizes. The surface of the comet displays regions of different strength where regions such as Seth and Anhur are relatively weakly consolidated as evident from the common occurrence of mass wasting deposits of various sorting (e.g., Giacomini et al. 2016; Lee et al. 2016; Fig. 3C), as opposed to more strongly consolidated regions that display a paucity of such deposits, and presence of large fracture systems (El-Maarry et al. 2016). In addition, consolidated terrains display evidence of layering and terracing on a whole-body scale (e.g., Massironi et al. 2015; Penasa et al. 2017).

The principle morphological trait of 67P is its hemispherical dichotomy, which is marked by a disparity of relief between the northern and southern hemispheres (see Sect. 2.1), as well as a morphological dichotomy highlighted by the uneven spatial distribution of non-consolidated materials (NCMs). The northern hemisphere appears to be predominantly covered by NCMs whose distribution and extent is most probably controlled by local gravitational slopes (Sect. 2.1). A thin layer (only a few metres thick at the most) of NCMs covers nearly $20 \%$ of the total comet's surface (Thomas et al. 2018), but is almost exclusively confined to the northern hemisphere. Smooth terrains represent locations where NCMs have accumulated into deposits that are thick enough to entirely cover the underlying topography and form quasi flat surfaces (e.g., Imhotep and Hapi regions, Fig. 3A). In contrast, the southern hemisphere appears to be devoid of largescale deposits of NCMs (El-Maarry et al. 2016); this difference is consistent with modelled predictions of seasonal activity-driven redistributions of NCMs (Keller et al. 2015; Thomas et al. 2015a). NCMs generally appear smooth in meters/pixel images as the predominant grain sizes are below imaging resolution. Sub-meter resolution images from both the orbiter and lander can resolve NCM grains down to the $\sim 5$ and $7 \mathrm{~cm}$ scale at the Agilkia (first landing site of Philae) (Pajola et al. 2016b) and Sais (final resting site of the Rosetta orbiter) (Pajola et al. 2017a), respectively.

The northern hemisphere and equatorial regions also include a number of large-scale depressions, which appear to be lacking in the southern hemisphere. Aten, one of the notable depressions in the large lobe is $\sim 0.12 \mathrm{~km}^{3}$ in volume (Thomas et al. 2015b, Fig. 3B). Thomas et al. (2015a) calculated that the production of Aten by a sublimation mechanism alone would require 10-20 orbits in the current configuration. As a result, they concluded that large scale depressions were formed by major mass loss events. El-Maarry et al. (2015b) arrived at similar conclusions based on the morphology of the depression floors and the bounding scarps. Other less conspicuous, yet larger in size, regional depressions include 

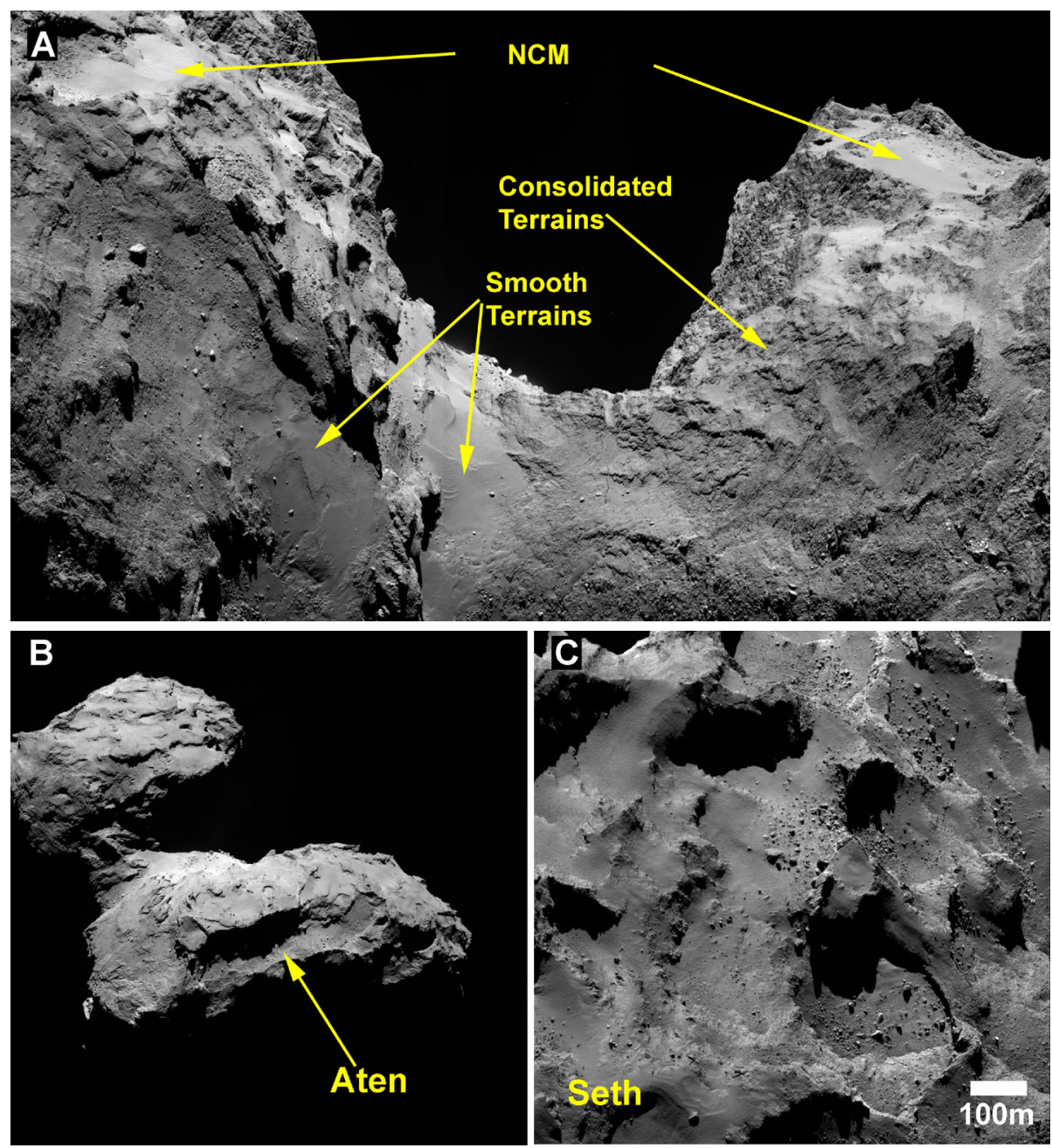

Fig. 3 (A) Mosaic of two Narrow Angle Camera (NAC) images displaying various terrain types on the northern hemisphere of 67P. "NCM" is an acronym for Non-Consolidated Materials. (B) NAC image showing the Aten depression in the northern part of the large lobe. (C) NAC image of the Seth region in 67P's large lobe (in the northern hemisphere) showing weakly consolidated materials as evident from the numerous arcuate and circular features, as well as ubiquitous talus deposits. Parts of Seth are covered in NCM deposits

the equatorial regions Imhotep, which is partially filled with smooth deposits, and Khonsu (Fig. 5), which shows a unique pancake-shaped structure that appears to have been exhumed through intense erosion (El-Maarry et al. 2016).

Other notable geomorphological features of the surface include circular pits, albeit predominantly in the northern hemisphere (Vincent et al. 2015a, Sect. 3.4), large-scale (100 s of $\mathrm{m}$ ) fracture systems, preferentially close to the neck region in both hemispheres (ElMaarry et al. 2015b, 2016), 10-100 s of meter-high cliffs (e.g., Hathor), and a dearth of unambiguous impact features. Comprehensive geological and/or geomorphological maps of the northern hemisphere, southern hemisphere and the nucleus as a whole have been published by Giacomini et al. (2016); Lee et al. (2016), and Birch et al. (2017), respectively. 


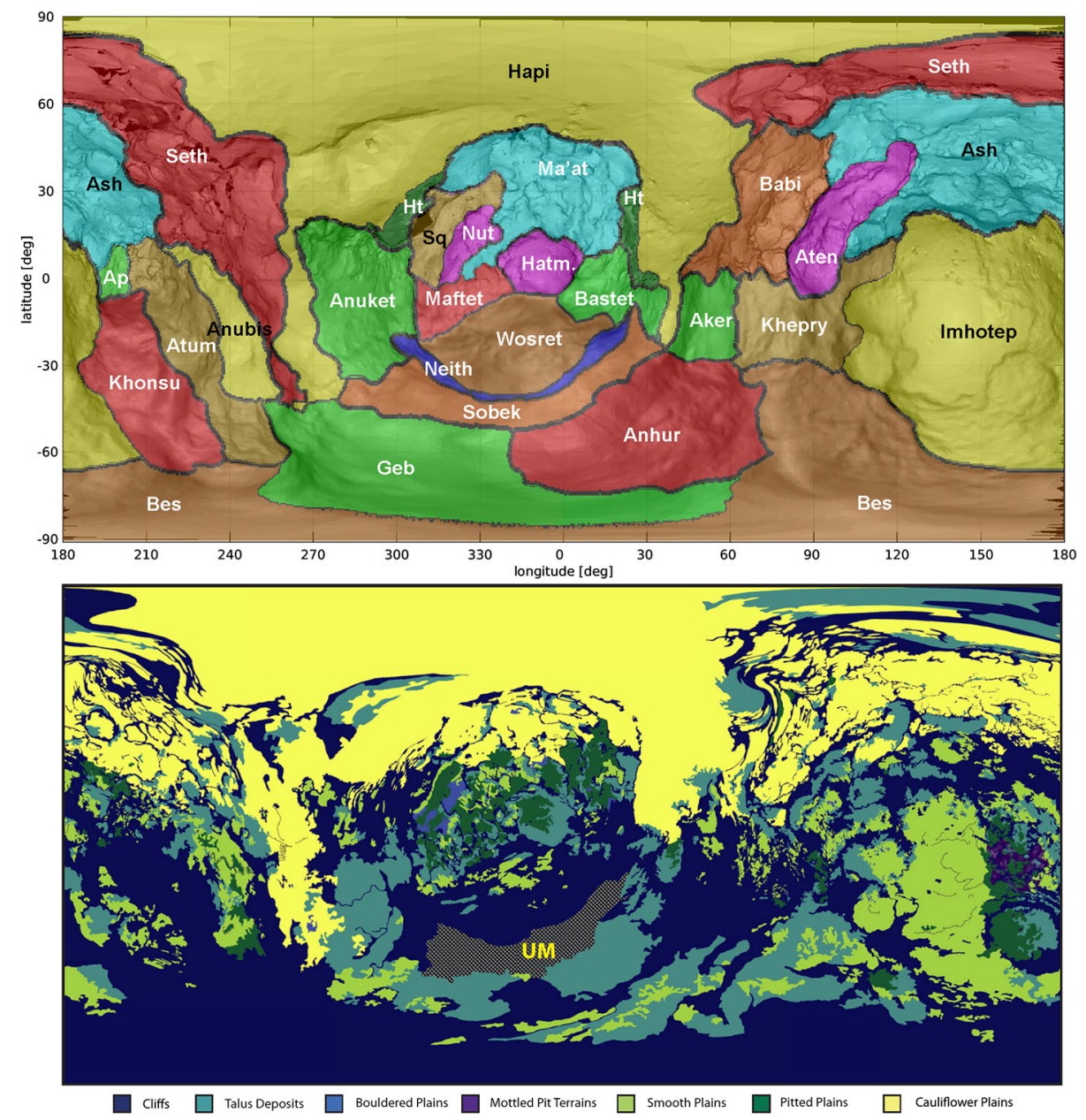

Fig. 4 Map projections of defined regions (top) adapted from El-Maarry et al. (2016), and global geomorphological map (bottom) adapted from Birch et al. (2017). Acronyms are as follows: (top) Ap: Apis, Ht: Hathor, Sq: Serqet, Hatm.: Hatmehit. (bottom) UM: Unmapped region in Birch et al. due to shadows in images that were available for the study

Briefly, Giacomini et al. (2016) identified 4 main geological units that comprise the northern hemisphere: (1) fine particle deposits (corresponding to the term "NCM" used in this revision), (2) consolidated materials, (3) smooth terrains, and (4) mass wasting deposits. Giacomini et al. (2016) further noted that the mass -wasting deposits had differing origins and size-sorting and so where classified into different sub-classes. Lee et al. (2016) carried a similarly comprehensive geologic mapping of the southern hemisphere describing similar units but noted that the southern hemisphere landscape was dominated by outcropping consolidated terrains. Finally, Birch et al. (2017) carried out an independent geomorphological mapping of the entire nucleus (Fig. 4) in which they identified the following units: (1) cliffs, essentially most of the exposed consolidated surfaces (2) talus deposits, (3) boulder-filled plains, (4) mottled pit terrains, a specific site in Imhotep containing circular features, (5) smooth plains, (6) pitted plains, and (7) "cauliflower" plains, roughly 
Fig. 5 The Khonsu region in the equatorial region of 67P's large lobe, which displays elevated, and sometimes sharp, boundaries and houses a pancake-shaped feature that appears to have been exhumed by erosion. Adapted from El-Maarry et al. (2016)

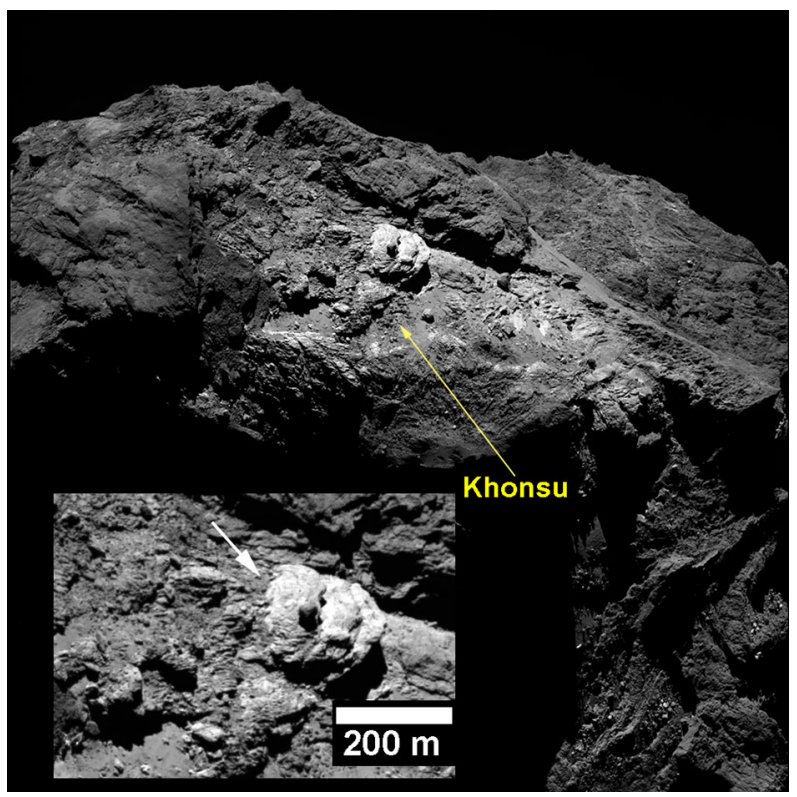

corresponding to the distribution of NCMs. In the next section we briefly describe the processes that acted on these terrains, and outline the major morphological changes that were observed by Rosetta during its mission.

\section{Surface Processes Affecting Morphology}

Comets display evidence for all fundamental geological processes, which include impact cratering, tectonism, and erosion (e.g., Bennet et al. 2017). We use the term 'tectonism' here to refer to processes that result in internal stresses on a (near-) whole body scale, as well as surface features that result from deformation caused by these stresses. The fourth fundamental geological process is conventionally volcanism, which is understandably absent on comets due to their small size (i.e. lack of significant decaying radioactive elements to supply internal heat). However, comets display sublimation-driven outgassing (Vincent et al. this volume). This process is comparable to volcanism on larger planetary bodies in that it provides a conduit for delivering materials from the interior to the surface. However, in the domain of active geological bodies, comets occupy a special niche since their geologic activity is almost exclusively driven by externally supplied energy (i.e. solar energy) as opposed to an internal heat source, which makes them "seasonally-active" geological bodies.

In the following sections, we review a number of morphologic features and their evolution (if changes were observed during the mission's lifetime) that are particularly indicative of active processes. Multiple processes may affect certain features simultaneously or with time. Therefore, rather than investigate each process individually, we focus instead on particular geomorphologic units and review the processes that collectively affect them. In this way, we can present a concise picture of how cometary materials evolve on diurnal, seasonal, and possibly longer, scales. Section 3.1 discusses the processes that affect consolidated materials, which may also consequently create NCMs, as well as associated features indicative of these processes. Section 3.2 moves on to discuss how NCMs further evolve with time 
Fig. 6 Potential pinnacles on comet 67P (arrows) with superposed color-coded values of gravitational slopes. Note that pinnacles appear to have slopes ranging from $40^{\circ}$ to $90^{\circ}$ (Basilevsky et al. 2017). The inset shows an example of a prominent pinnacle. Figure is adapted from Basilevsky et al. (2017)

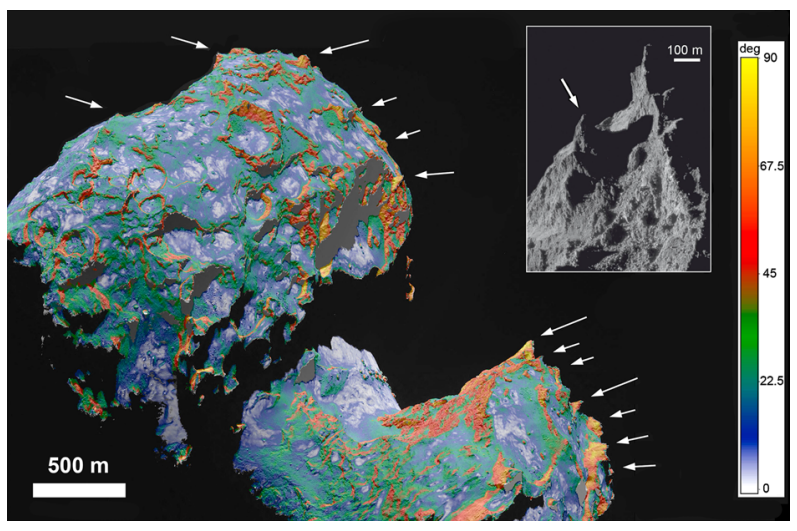

and the features associated with the active processes acting on NCMs. Section 3.3 discusses impacts as a unique process since it is an exogenic process that should affect all terrain types.

\subsection{Consolidated Terrains}

While consolidated terrains appear to represent the bare surface of the comet, it is probable that physical and chemical processes are responsible for their formation in the first place. Earlier studies that used various modeling approaches and lab experiments to simulate the evolution of cometary nuclei suggest that cometary materials may become "consolidated" by sintering of ice or re-condensation of sublimated water vapor following sublimation. For instance, "Kometen-Simulation" (KOSI) experiments (e.g., Kochan et al. 1989; Sears et al. 1999), and follow-up experiments, demonstrated that such a process in the lab leads to (1) hardening of the near-surface ice layer (e.g., Kossacki et al. 1999; Kossacki et al. 1997; Seiferlin et al. 1995), (2) increase of thermal conductivity, especially in the presence of organics (e.g., Kömle et al. 1996), and (3) development of a millimeter-thick surface dust layer (e.g., Grün et al. 1993; Kossacki et al. 1997; Pommerol et al. 2015a). Indeed, measurements by other instruments on Rosetta such as MUPUS and SESAME (both on the Philae lander) are consistent with consolidated materials having properties resulting from sintering as described above (Lethuillier et al. 2016; Spohn et al. 2015). This is discussed further later in Sect. 4.3. Continuous imaging and follow-up morphological investigations have not yielded enough information about the activity and effectiveness of such a process with time. However, sintering appears to be currently the most reasonable hypothesis for the formation of the consolidated materials despite remaining poorly understood particularly beyond controlled laboratory settings (e.g., Keller and Markiewicz 1991).

Following their formation, and in the presence of active geologic processes, weathering is probably the first process that acts on 67P's consolidated materials. In the absence of liquid water, weathering would be constrained to mechanical breakdown of materials. Indeed, Rosetta has observed evidence for weathering as fracturing and fragmentation leading to eventual erosion through mass wasting. We discuss these features below.

\subsubsection{Weathering and Pinnacles}

Pinnacles are local promontories of various shapes including spires with pointed tops (e.g., Migon 2004). They are likely erosional remnants created by a loss of material surrounding 
spots of the more-erosion-resistant material. Pinnacles (Fig. 6) were initially identified and described by Basilevsky et al. (2017) in 67P's northern hemisphere. Basilevsky et al. (2017) identified 49 pinnacles (Fig. 6) in 67P's northern hemisphere. They are generally asymmetric in shape with heights ranging from $10 \mathrm{~m}$ to $200 \mathrm{~m}$ (40 m as a mean value), and foot diameters ranging from $30 \mathrm{~m}$ to $300 \mathrm{~m}$ (60 m as a mean value) (Basilevsky et al. 2017). Pinnacles possibly represent an intermediate stage of weathering of strongly consolidated material whereas weaker consolidated units react to weathering more readily by fracturing and eventual fragmentation.

\subsubsection{Fracturing and Polygonal Networks}

Fractures are ubiquitous on the exposed consolidated surfaces of 67P forming various patterns and topologies at different size-scales (El-Maarry et al. 2015a). Fracture networks on planar surfaces are the most common setting of fractures on 67P (Fig. 7). Sub-meter-wide fractures form 2-dimensional surface patterns with different topologies. They vary in length from $100 \mathrm{~s}$ of meters down to mm-scale as observed by the Philae lander (Bibring et al. 2015; Poulet et al. 2016).

Fractures often intersect to form polygonal networks, modes of intersection are variable but include orthogonal intersections, which are a common indicator of slowly building stress regimes in which fractures form slowly and consequent to one another instead of a more rapid and simultaneous manner (El-Maarry et al. 2015b). In a preliminary analysis of images from orbit, El-Maarry et al. (2015b) noted the presence of hummocky features embedded within fracture networks that could be indicative of high-centered thermal contraction-like polygons. A near-global mapping of more than 6000 of these features by Auger et al. (2018) indicated that they are ubiquitous at all latitudes and longitudes. The size of the polygons ( $90 \%$ of the mapped features) is predominantly 1-5 meters in width although few features exceed $13 \mathrm{~m}$. The fractures intersect in both 3-ray (i.e., $\sim 120$ degrees), and 4-ray (orthogonal or near orthogonal) manner, with 3-ray intersections being more common (Auger et al. 2018). El-Maarry et al. (2015b) favored an insolation weathering mechanism for the formation of fracture networks based on simple thermal models and the features' morphology and settings. Auger et al. (2018) utilised a more complex thermal model and concluded that polygonal fracture systems were consistent with a seasonal thermal contraction mechanism caused by variations in insolation on daily and seasonal scales, similar to what is observed in periglacial/glacial landscapes on Earth and Mars.

Fracture networks have also been observed at the mm scale by cameras onboard Philae at its final landing site. However, these smaller fractures form poorly-developed networks that lack well-defined polygonal shapes (Poulet et al. 2016). The longest fractures reach up to $10 \mathrm{~s}$ of $\mathrm{cm}$ in length with an average of $\sim 20 \mathrm{~mm}$ in rough units and $\sim 45 \mathrm{~mm}$ in relatively smoother units (Poulet et al. 2016). Given the wide-spread of fracturing in the surface of 67P, spanning many length scales, it is safe to assume that fracturing processes play a primary role in the mechanical weathering of consolidated surface materials. As fractures present preferential zones of weakness, they become the point of focus for continuing breakdown leading to eventual failure such as collapsing of cliffs and formation of poorly sorted nonconsolidates debris (i.e. boulders).

\subsubsection{Mass Wasting and Boulder Formation}

Fractures of a more irregular pattern are observed on the edges of scarps (Fig. 8) particularly in weakly consolidated units. The bases of fractured scarps display debris and talus deposits, indicating an ongoing process of mass wasting associated with weakly consolidated 
Fig. 7 Polygonal fracture patterns in consolidated materials. Figure is adapted from El-Maarry et al. (2015b). Note the embedded features in panels $\mathbf{a}$ and $\mathbf{b}$, which could be a result of thermal contraction processes
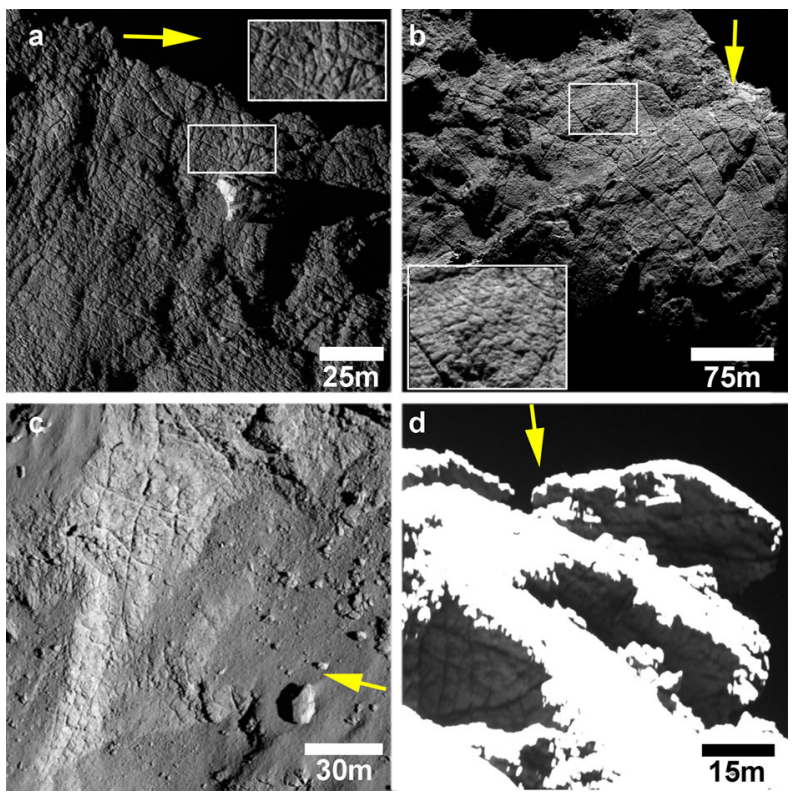

units (El-Maarry et al. 2015b). During the mission, two sites of fractured cliffs displayed mass wasting events marked by detachment of materials at the fractured site (Pajola et al. 2017b; El-Maarry et al. 2017, Fig. 9), highlighting the role of such fractures in mass wasting events. The approximate timing of theses collapses is consistent with periods of large diurnal temperature fluctuations, which are particularly pronounced close to perihelion when these cliffs likely collapsed (El-Maarry et al. 2017; Pajola et al. 2017b). ${ }^{3}$ Such mass wasting events should be the primary process by which cometary materials are being fragmented. Indeed, one of the main morphological features characterising the nucleus of $67 \mathrm{P}$ is the widespread presence of boulders (Pajola et al. 2015).

Early in the mission, more than one hundred bright boulders were observed in the comet's northern hemisphere (Pommerol et al. 2015b). These boulders were up to ten times brighter than the average surface of the comet at visible wavelengths and their spectrophotometric properties were consistent with exposure of water ice (Pommerol et al. 2015b). These bright boulders were either observed as (1) clusters, particularly in association with talus, (2) isolated boulders, or (3) partially bright boulders that displayed only bright patches on the surface (Pommerol et al. 2015b). The clustered bright boulders in particular, offer direct evidence for common, and recent, mass wasting events.

Studies focused on boulder counting and characterisation resulted in global sizefrequency distributions (SFD) of boulders $\geq 7 \mathrm{~m}$ in size (Pajola et al. 2015, 2016b, Fig. 10A), as well as local SFD studies of sizes $\geq 2 \mathrm{~m}$ (Pajola et al. 2016c, Fig. 10B) down to even the decimeter and centimeter scales (Pajola et al. 2016a, 2017a). The numerous studies focused on boulders suggest that their SFD can be indicative of their formation processes and how the surface of 67P evolves. Indeed, Pajola et al. (2015, 2016b) identified that whenever there is a collapse/pit formation and creation of depressions with subsequent escape

${ }^{3}$ Close to perihelion in August 2015, Rosetta was moved to higher orbits for its safety due to the intense activity of the comet. Unfortunately, this resulted in a decrease of image resolution and coverage. Therefore, the exact timing of certain surface changes is uncertain and can only be constrained to a certain time-frame. 

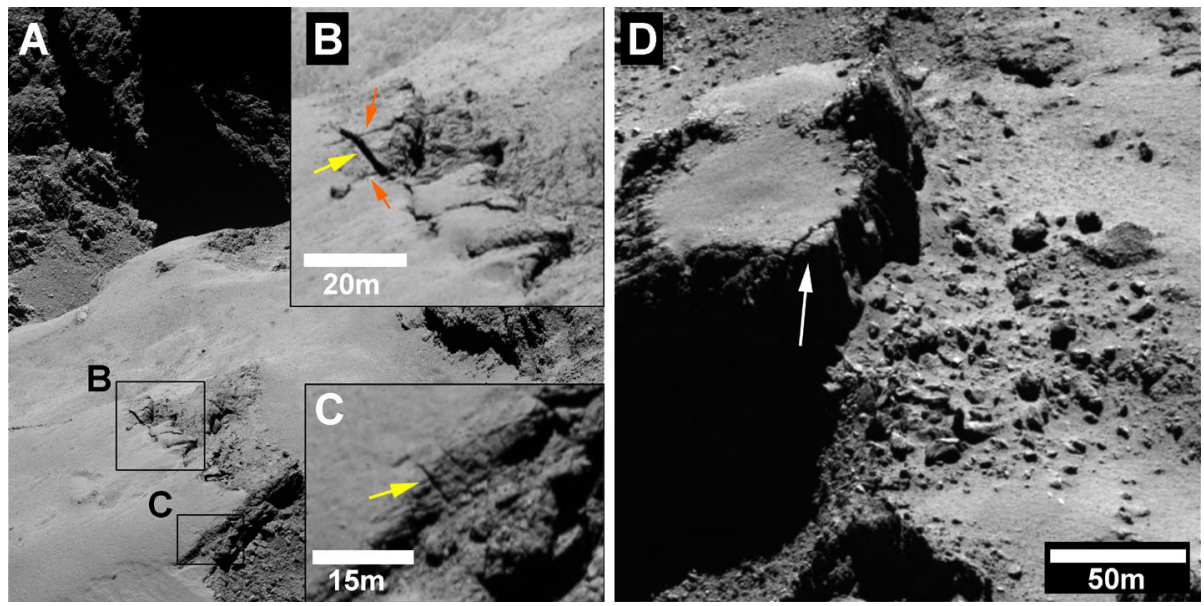

Fig. 8 Fractures in proximity to cliffs or small scarps. Note the debris field in (D) at the base of a fractured cliff, which suggests a continuous process of mass wasting. Figures adapted from El-Maarry et al. (2015b)
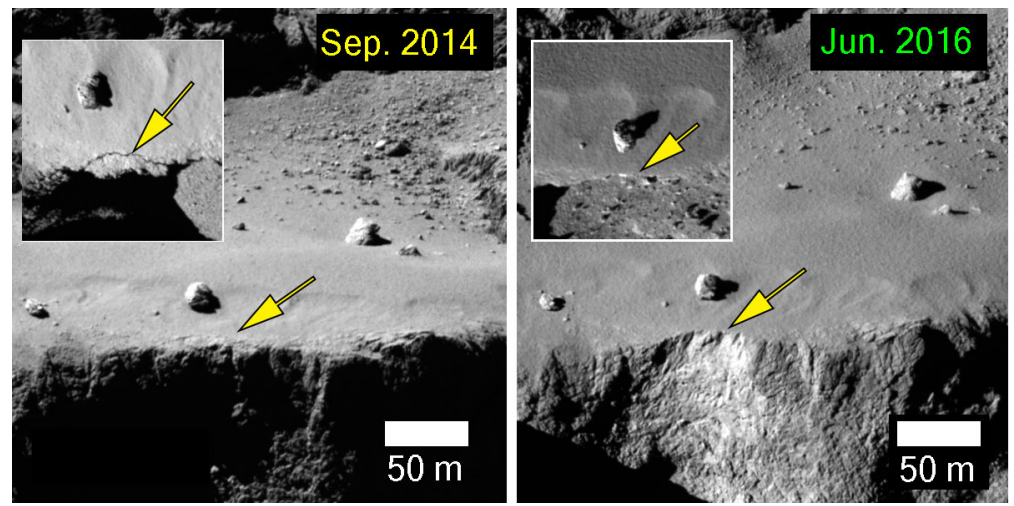

Fig. 9 The collapsing cliff in the area dubbed Aswan (Pajola et al. 2017b). The cliff collapse was triggered by the failure of a long arcuate fracture near the scarp. Figure adapted from El-Maarry et al. (2017)

of high-pressure volatiles and consequent high fracturing, the boulders SFD range between -5 and -6.5 (called type 1 boulders). On the other hand, gravitational events triggered by sublimation and/or thermal fracturing causing cliff collapses and regressive erosion result in power-law indices between -3.5 and -4.5 (called type 2 boulders). Further evolution of the original material formed during collapsing events results in indices of about -1 to -2 (Pajola et al. 2015). The global 67P boulder power-law index of $-3.6+0.2 /-0.3$ suggests that type 2 boulders are dominant on the comet, and hence its surface may well be shaped by progressive erosion and receding of its cliffs (Pajola et al. 2015, 2017b).

\subsubsection{Tectonism and Associated Features}

While most fractures observed in 67P's consolidated materials form polygonal networks suggestive of a global homogenous process, certain fracture systems show a unique setting that may be indicative of internal stresses acting on the whole body but leading to surface 

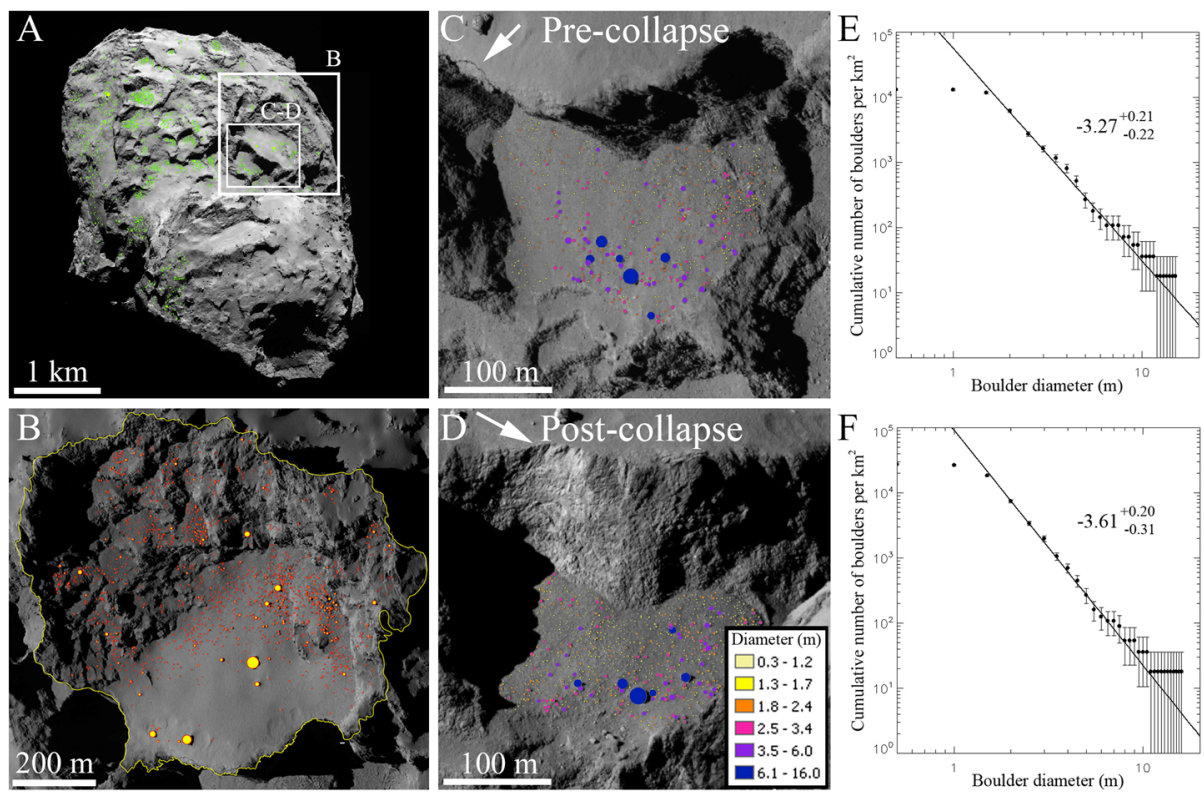

Fig. 10 Fig. 1: (A) Boulders $\geq 7 \mathrm{~m}$ identified on specific areas on 67P (Pajola et al. 2015). Insets show location covered by panels (B)-(D). (B) Spatial distribution of the boulders $\geq 2 \mathrm{~m}$ identified in the Aswan site (Pajola et al. 2016c). (C) Pre-collapse spatial distribution of boulders $\geq 1.5 \mathrm{~m}$ identified below the Aswan cliff. Arrow points to the section that would later detach. (D) Post-collapse spatial distribution of the boulders $\geq 1.5 \mathrm{~m}$ located on the new talus formed below the Aswan cliff. Arrow points to location of detachment. $(\mathbf{E})$ and $(\mathbf{F})$ Cumulative number of boulders per $\mathrm{km}^{2}$ identified in $(\mathbf{C})$ and $(\mathbf{D})$, respectively. The corresponding power-law indices of the fitting curves are also presented. Panels (C) and (D) adapted from Pajola et al. (2017b)

expressions at particular zones where stresses would be concentrated. The most prominent example of this process is the $>500 \mathrm{~m}$-long fracture system in the northern neck region (Thomas et al. 2015a). El-Maarry et al. (2017) reported that this fracture system had extended by $\sim 30 \mathrm{~m}$ in length at a time consistent with the period when the comet's orbital period decreased (i.e. its spin rate increased). Other fracture systems such as those observed in Hathor cliffs, the angular fracture observed in the Khepry region (El-Maarry et al. 2015a) and large fractures in the southern hemisphere close to the neck region and perpendicular to the comet's long axis (El-Maarry et al. 2016) could either be other manifestations of tectonic processes or the result of external collisions during 67P's past orbital evolution (El-Maarry et al. 2015a).

\subsection{Non-consolidated Materials}

As discussed earlier, non-consolidated materials (NCMs) are probably the heavier weathering products of consolidated materials that are initially ejected from the surface and then re-deposited predominantly in the northern hemisphere. They form two distinctive settings depending on topography, which controls the deposit thickness: thin (probably up to a few meters thick) deposits covering topographically high (with high gravitational potential) regions form the so-called dust layers (e.g., Thomas et al. 2015b). Areas with low gravitational potential allow NCMs to pond into thick deposits forming "smooth terrains" (e.g., Thomas et al. 2015b). While the NCMs forming both settings are expected to be of the same initial 

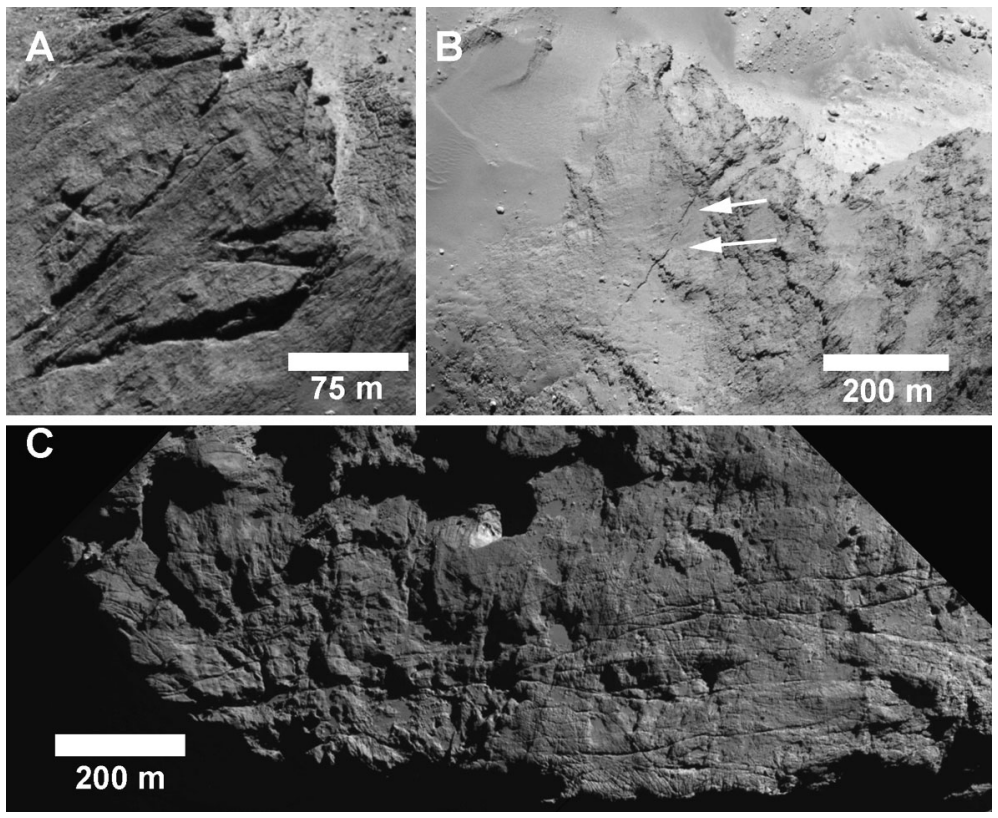

Fig. 11 Large-scale tectonic features on 67P. (A) Angular fracture system on the large lobe in the Aker region (El-Maarry et al. 2015a). (B) Long fracture system in the neck region, which was observed to lengthen during the course of the mission (El-Maarry et al. 2017). (C) Long hundreds-of-meters-long fractures in the small lobe's southern hemisphere in the Wosret region (El-Maarry et al. 2016)

composition (with respect to ice-to-dust ratio and concentration of organics), it is possible that their setting and thickness may affect the way they evolve and the degree to which they are affected by weathering and erosion. The NCMs display transient changes (potentially caused by weathering) that appear to be unique to comets. However, NCMs in particular locations also display evidence for erosion and re-mobilisation. In the case of NCMs, coma-surface interactions have arguably a bigger role in driving evolution than they do with consolidated materials.

\subsubsection{Outgassing: Conventional Cometary Activity and Associated Features}

Historically, the term "activity" in cometary science was used exclusively to describe relatively bright (with respect to the nucleus and surrounding coma) sublimation-driven outgassing events that create and maintain a transient coma around the nucleus when the comet is sufficiently close to the Sun. Conventional cometary activity displays numerous morphologies ranging from highly collimated to diffuse, as well as a wide range of sizes depending partly on whether the features are resolved in close flyby/orbiting spacecraft images, or Earth-based observations (see Vincent et al., this volume). Vincent et al. (this volume) classify the classical form of cometary activity into perennial collimated streams, and transient plumes. The distinction is based essentially on their physical shape and temporal behavior irrespective of their size, source region, or sublimating species (e.g., $\mathrm{CO}_{2}$ vs. $\mathrm{H}_{2} \mathrm{O}$ ). For this chapter, we are primarily interested in how such activity affects surface morphology and potentially drives its evolution. Cometary activity can act as both a depositional and erosional process. There is clear evidence for the activity's depositional after effects as evident 

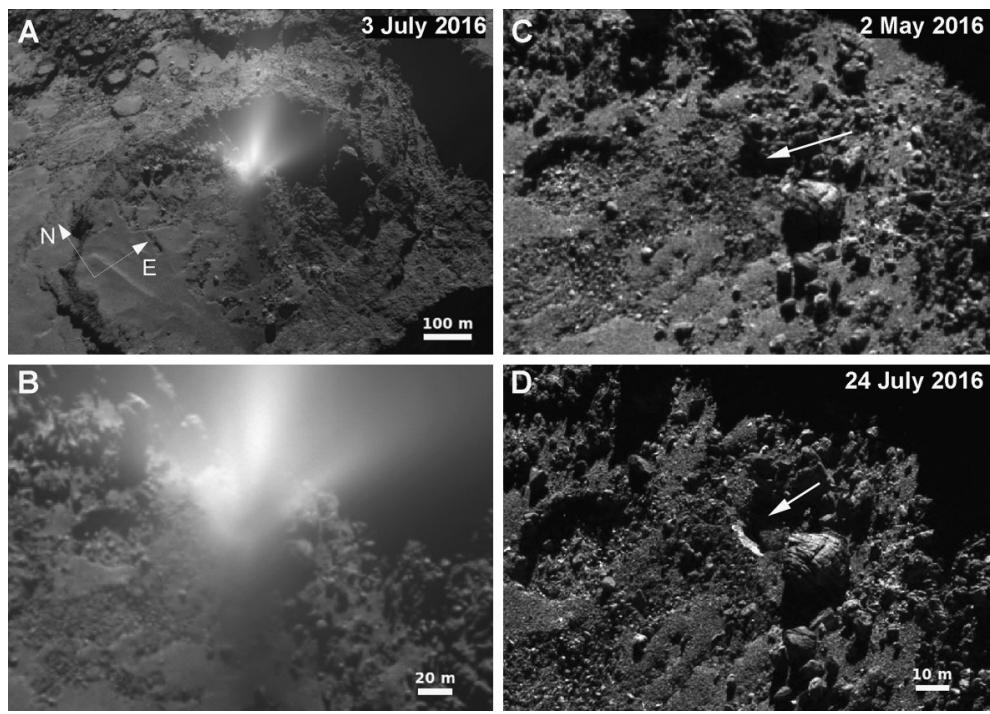

Fig. 12 Outburst in the Imhotep region in July 2016 (adapted from Agarwal et al. 2017). (A) Bright outburst in the Imhotep region. (B) Close-up view of the event. (C) Area before the outburst in May 2016. Arrow points to the location of outburst that would occur nearly one month later. (D) View of the area a few weeks after the event. Note the bright patch of water-ice

from the ubiquitous distribution of NCM in the northern hemisphere and equatorial region. Materials that get entrained along with the energetic streams and plumes will either contribute to the comet's coma or in the case of heavier blocks, settle back on the surface to create the air-fall-like deposits (see Fig. 3). With respect to the activity's erosional effects, Rosetta's results have been more ambiguous. Two prominent examples that were reported are the dust plume in temporal association with the collapsing cliff of Aswan (Sect. 3.1.3, Pajola et al. 2017b), and the small outburst of activity reported by Agarwal et al. (2017) in the equatorial region of Imhotep (Fig. 12). While it is difficult to draw concrete conclusions from the cliff collapse since the available images do not possess adequate temporal resolution to verify whether the activity drove the cliff collapse or if the dust plume was a result of the cliff collapse, it is possible to infer from the outburst in Imhotep more information on how activity affects the surface. In this particular example, an outburst of activity in 3 July, 2016 lasted for 14-68 min in the Imhotep region, and left behind an ice patch of approx. 10 meters in size (Fig. 12, Agarwal et al. 2017). The resulting morphology would suggest that such outbursts result in the erosion of surface materials and exhumation of near-surface ice. Similarly, bright features were also apparent in another equatorial region, Khonsu, after a series of outbursts in the region (Deshapriya et al. 2016), which may suggest a similar mechanism despite lacking a similar temporally resolved dataset like that of Imhotep. In addition, the movement of a large $30 \mathrm{~m}$-wide boulder in the Khonsu region may have been triggered by erosion from such events (El-Maarry et al. 2017). In short, conventional activity on comets appears to act as both an eroding and transporting agent removing materials from their source location and transporting them into the coma. Some materials would eventually resettle in areas of low gravitational potential. Other forms of erosion are discussed in a later section. As materials get ejected by streams and plumes and later are re-deposited, they undergo further evolution, which is discussed next. 

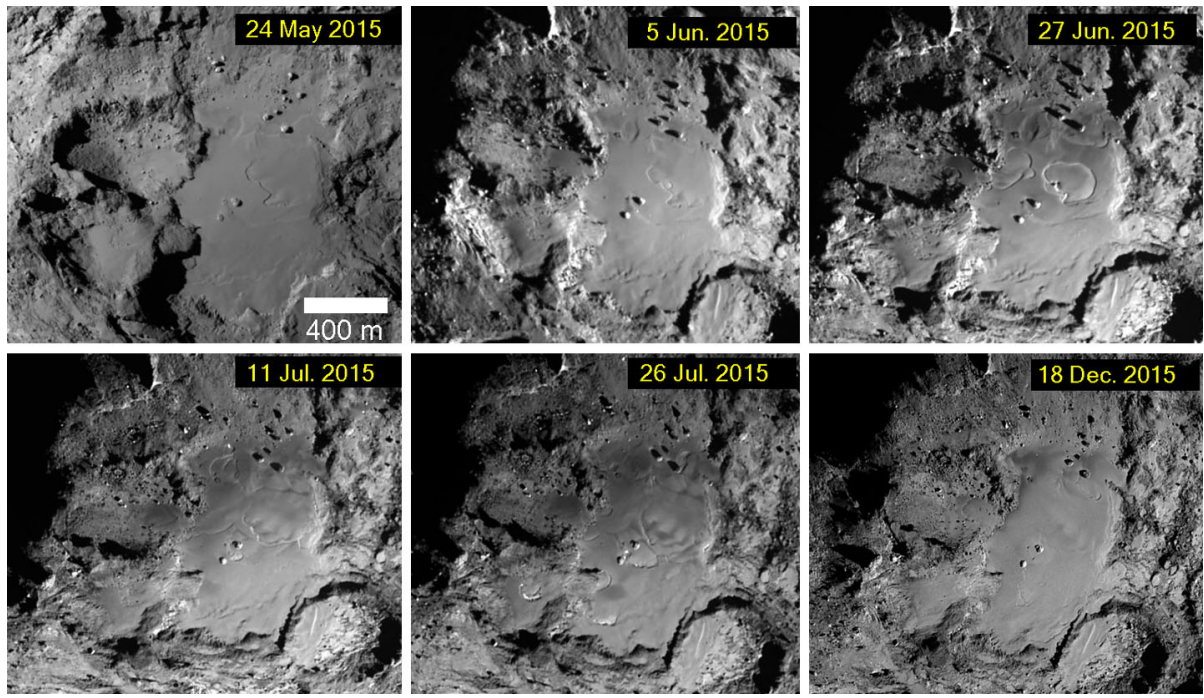

Fig. 13 Transient surface changes in the smooth terrains of Imhotep first reported in Groussin et al. (2015). Figure adapted from El-Maarry et al. (2017)

\subsubsection{Transient Surface Changes}

The NCM covers most of the northern hemisphere, and consists predominantly of redeposited ejected materials. NCM evolved in various ways throughout the mission depending on their setting. Smooth terrains are located in the northern hemisphere, particularly within gravitational lows in the Imhotep, Anubis, and Hapi regions (Fig. 4; Sect. 2.2). An in-depth analysis of the smooth terrain at Imhotep indicates that the terrains have low gravitational slopes ( $<5$ degrees) (Auger et al. 2015). The deposits are mainly composed of grains/blocks of variable sizes with larger grains reaching tens of $\mathrm{cm}$ in width (Auger et al. 2015). The smooth terrains of Imhotep displayed one of the earliest remarkable transient surface changes (Fig. 13, Groussin et al. 2015). In early June 2015, nearly two months before perihelion, roundish features appeared in the smooth terrain and expanded in nearly circular fashion in the following days. The features would eventually reach $100 \mathrm{~s}$ of meters in width and few meters in depth. Groussin et al. (2015) calculated expansion rates ranging from 4.3 to $7.6 \mathrm{~m} /$ day for two of such features, and noted that these rates were constant between observations. These rates are more than one order of magnitude faster than the erosion rate of pure $\mathrm{H}_{2} \mathrm{O}$ or $\mathrm{CO}_{2}$ ice (Groussin et al. 2015), which suggests that erosion may not be occurring by water-ice sublimation. Within a few months, almost all the Imhotep smooth terrains (nearly $1 \mathrm{~km}^{2}$, Auger et al. 2015) had been affected by these changes. If we consider an average height of mobilized materials of $5 \mathrm{~m}$ (Groussin et al. 2015), and an average density of $532 \mathrm{~kg} / \mathrm{m}^{3}$ (Jorda et al. 2016), this would correspond to roughly $2.7 \times 10^{9} \mathrm{~kg}$ of mobilized materials. This value is comparable to the total amount of water released by the comet in a single orbit (Bertaux 2015), which suggests that most of the materials mobilized during these transient changes did not escape the nucleus.

The transient changes in the Hapi region were morphologically similar to those observed at Imhotep, although they started 5 months before, at 2.6 a.u. from the Sun instead of 1.6 a.u. in Imhotep's case (El-Maarry et al. 2017). They also involve development of roughly circular depressions, expanding with time at a rate incompatible with the erosion rate of 

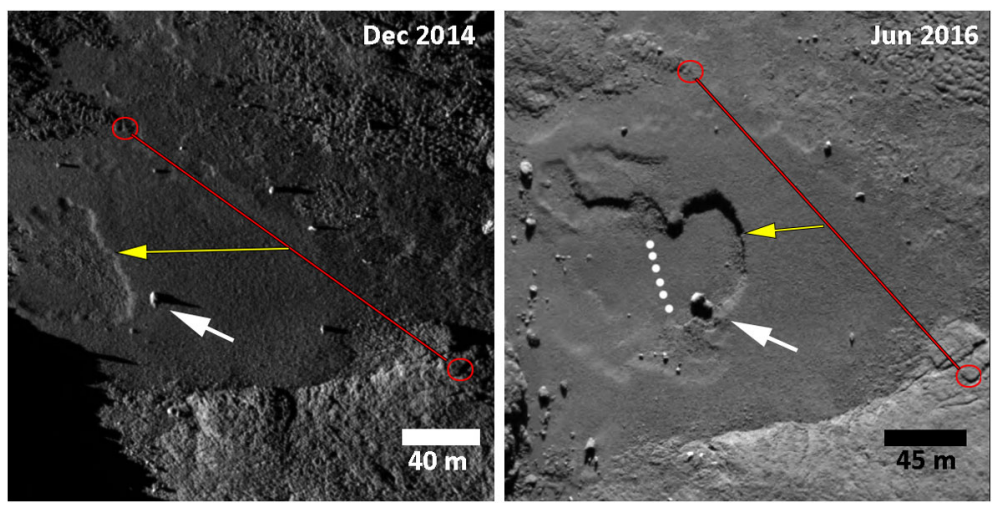

Fig. 14 Erosion by scarp retreat in the Anubis region. The scarp shown has retreated by approx. $50 \mathrm{~m}$ in total (yellow arrow). A boulder is shown (white arrow), which may have been dislodged form its original location through the erosion. Figure is adapted from El-Maarry et al. (2017)

pure $\mathrm{H}_{2} \mathrm{O}$ or $\mathrm{CO}_{2}$ ice at that heliocentric distance. One of the most prominent features that developed in the Hapi region was a circular feature that grew to nearly $100 \mathrm{~m}$ in width from April to July 2015. During its growth, its scarps displayed brightening suggestive of exposed water-ice (El-Maarry et al. 2017). However, when changes had stopped, the smooth terrains had nearly returned to its initial form prior to the changes. One possible reason for this would be deposition/ponding of new NCMs ejected from the southern hemisphere around perihelion (El-Maarry et al. 2017). El-Maarry et al. (2017) reported other changes in the smooth terrains of Anubis (Fig. 14). However, in the Anubis region, scarp retreats (also displaying brightening during their evolution) were observed in pre-existing shallow depressions, reaching $50 \mathrm{~m}$ (Fig. 14, El-Maarry et al. 2017), which were reminiscent of similar changes with respect to morphology, scale and setting, at comet Tempel 1 (e.g., Thomas et al. 2013a).

With regards to thinner deposits of NCM such as those in the Ma' at region, the nature of the transient changes in them was different from that in the smooth terrains. These changes occurred in the form of modification of the texture of the terrain, which became rougher during the period of changes (few months), forming "honeycomb" structures (Hu et al. 2017; Shi et al. 2016, Fig. 15). The eroded areas measure typically a few tens to a hundred meters and are all located in the northern hemisphere, between latitudes $20^{\circ} \mathrm{N}$ and $40^{\circ} \mathrm{N}$. A digital terrain model for one of these patches indicated vertical erosion of $0.5 \mathrm{~m}$ on average $(\mathrm{Hu}$ et al. 2017). The dependency on solar insolation is supported by the fact that the latitude of these changes coincided temporally with sub-solar latitude over the surface (Hu et al. 2017). However, there is no sign of bluing (i.e. exposed ice) during the changes.

\subsubsection{Aeolian-Like Processes and Associated Features}

The unambiguous observation of aeolian-like features at the surface of 67P was somewhat unexpected. The comet, and particularly its northern hemisphere, contains a substantial amount of NCMs, which in theory could be mobilized in a low gravity regime. However, comets display a very low gas density compared to planetary objects which possess such features, and most of the gases escape radially (Kuehrt and Keller 1994). Nevertheless, mechanisms of grain transport and aeolian erosion occurring at the surface of comets were 

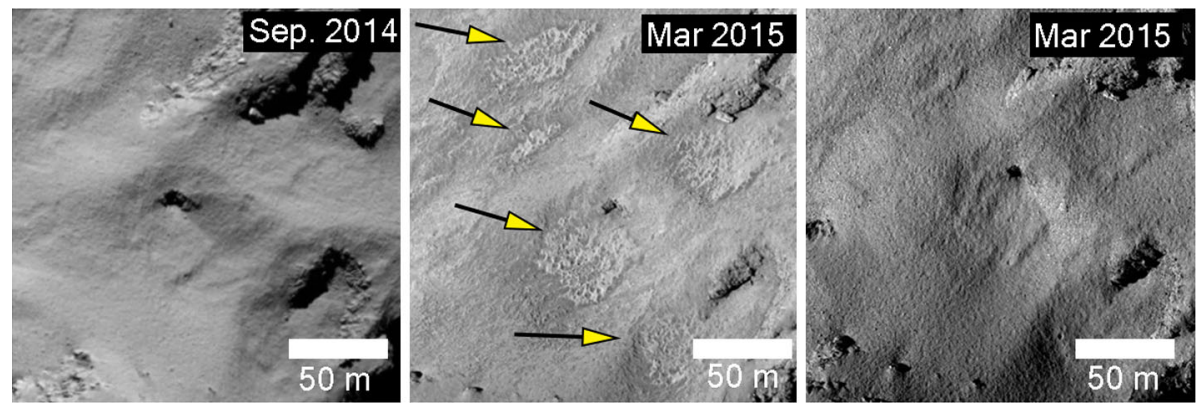

Fig. 15 "Honey-comb" structures in the thin NCM coatings in the Ma'at region. Figure adapted from ElMaarry et al. (2017)

previously considered prior to the Rosetta mission, and evaluated by analogy with study on classical aeolian processes (Cheng et al. 2013).

The most striking examples of aeolian-like landforms on comet $67 \mathrm{P}$ are the ripples on the surface of the NCMs covering the neck region of Hapi, first identified in 2014 shortly following the arrival of Rosetta (Fig. 16, Thomas et al. 2015b). At that time, the length of the ripples field was $\sim 100 \mathrm{~m}$ with a width of $\sim 60 \mathrm{~m}$ (Thomas et al. 2015a). The bedforms had characteristic asymmetric profiles with small steep lee side and a longer and gentle slope on the stoss side (Jia et al. 2017; Thomas et al. 2015a). The longest axis of crests was roughly aligned E-W (Giacomini et al. 2016) with a mean wavelength of $\sim 7-18 \mathrm{~m}$ for different bedforms (Thomas et al. 2015a, 2015b, Jia et al. 2017). The amplitude of the larger ripples was estimated to be $22 \pm 12 \mathrm{~cm}$ (Thomas et al. 2015a). The aspect ratio, i.e. the ratio between the amplitude and the wavelength of the wave, lay between 0.02 and 0.04 (Thomas et al. 2015a) which is the order of magnitude of aspect ratios of ripples and dunes on other planets (e.g., Ellwood et al. 1975). As the comet approached perihelion these features disappeared (around April 2015) and circular pits developed instead, and extended (El-Maarry et al. 2017). After perihelion, the circular pits vanished and a new set of ripples developed at the same place of the previous ones (Fig. 16). The wavelength of the new ripples field is on average $\sim 16-20 \mathrm{~m}$ (Jia et al. 2017). The formation of these ripples has been attributed so far to either a "splash" effect of dust grain due to dust air-fall (Thomas et al. 2015a), or saltation/reptation of grains due to lateral outgassing at the surface produced by pressure differences due to varying illumination conditions (Cheng et al. 2013; Thomas et al. 2015a; Jia et al. 2017). Other ripple formations have also been observed in other locations such as in Maftet and Ma' at (Jia et al. 2017).

Other candidate aeolian features were observed on the surface of the comet on both lobes (La Forgia et al. 2015; Giacomini et al. 2016; Hu et al. 2017; Jia et al. 2017). On the small lobe, dust deposits appear to have experienced dust mobilization/redistribution, especially in the regions of Ma' at, Nut, Maftet and Hatmehit (La Forgia et al. 2015; Giacomini et al. 2016; Keller et al. 2017; Thomas et al. 2015a). In these regions dune-like features formed on flat areas $\left(<10^{\circ}\right.$ of gravitational slope) covered by smooth material composed of centimeters scale grains (Jia et al. 2017; Mottola et al. 2015) that exhibit local heterogeneities (Thomas et al. 2015a). Aeolian-like bedforms are arranged in fields showing a preferential and consistent orientation of their longest axis through the whole area (La Forgia et al. 2015; Thomas et al. 2015a; Giacomini et al. 2016). They were interpreted to be analogous to longitudinal dunes (La Forgia et al. 2015; Thomas et al. 2015a; Giacomini et al. 2016).

Finally, more than 60 wind-tail like features and moats have been observed around large $(>5 \mathrm{~m}$ ) boulders located among the NCM deposits (Mottola et al. 2015; Thomas et al. 


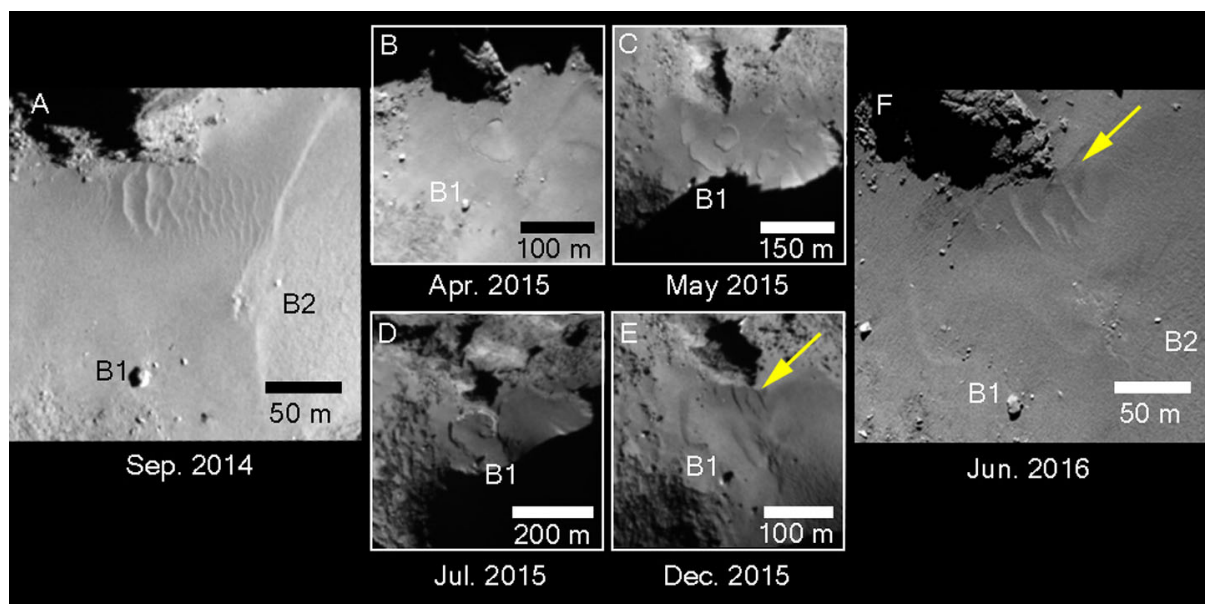

Fig. 16 Evolution of the ripples (A) in the Hapi (northern neck) region of 67P. Surface modifications in the form of developing circular features (B)-(D) started in April 2015 at the earliest and continued through the perihelion passage (in Aug. 2015). New ripples developed in Dec. 2015 at the earliest (E), (F). Two prominent boulders (B1 and B2) are marked for orientation. Figure adapted from El-Maarry et al. (2017)

Fig. 17 Wind-tail-like features on 67P. Figure adapted from Tirsch et al. (2017)

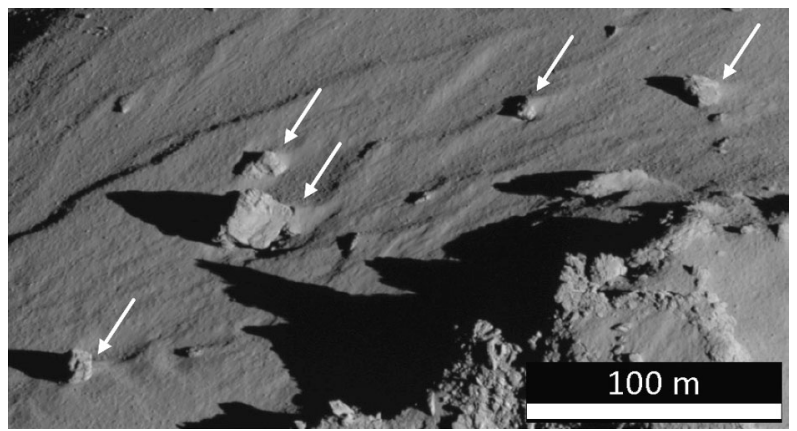

2015a,2015b; Tirsch et al. 2017, Fig. 17). These features appear as triangular shaped aprons of fine debris (Mottola et al. 2015). In the Ma' at region, the wind-tail lengths on Ma' at (near the initial Philae landing site) were reported to be 5-30 $\mathrm{m}$ in length, with a maximum height of approximately one third of the boulder height with the wind-tails generally pointing in the south-north direction (Mottola et al. 2015). Follow up analysis by Tirsch et al. (2017) of nearly 60 wind-tail features yields an average length of $13.7 \mathrm{~m}$. Despite the apparent abundance of wind-tail-like features, many NCM-covered areas on 67P with an abundance of boulders do not show any aeolian-like features, suggesting that the processes that form these features are spatially constrained.

\subsubsection{Localised Erosion and Exhumation}

Certain locations in the smooth terrains (i.e. accumulated NCMs) display evidence for higher than average vertical erosion that reaches a few meters. Examples of this localized erosion include the scarp retreats in the Anubis region (Sect. 3.2.2, Fig. 14) and the circular features that developed in the Hapi region that led to the destruction and reformation 

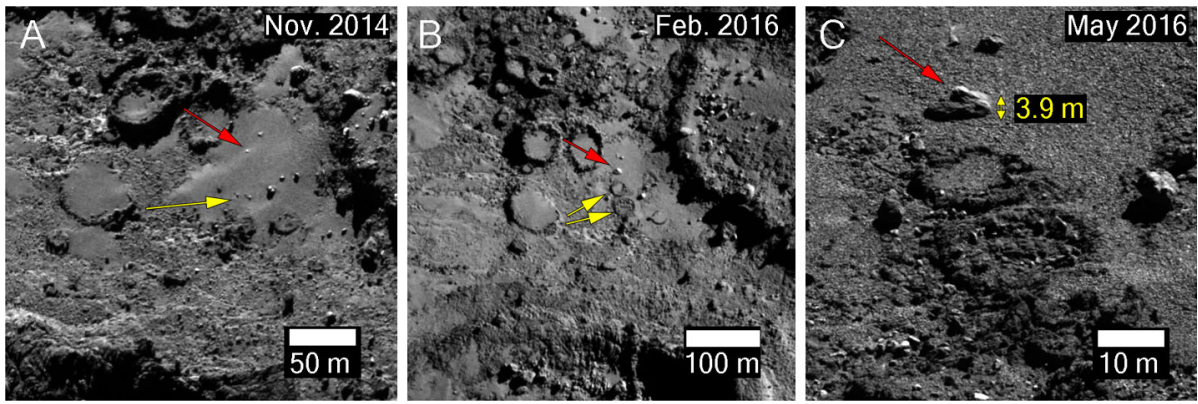

Fig. 18 Erosion in the Imhotep region. A thin coating of NCM (A) was removed (mainly around perihelion) leading to the exhumation of previously covered circular features (yellow arrows), and partially buried boulders (B). One of such boulders (red arrow in all panels) was used to estimate the vertical extent of erosion in that particular location by measuring the height of its previously buried section $(\mathbf{C})$. Figure adapted from El-Maarry et al. (2017)

of aeolian-like features (Sect. 3.2.3, Fig. 16). In Anubis, the vertical erosion resulted in the widening of a previously existing shallow irregular depression by scarp retreat (Fig. 14, ElMaarry et al. 2017). The depressions that have widened by $\sim 50$ meters have a depth of 4-5 meters (El-Maarry et al. 2017).

A similarly remarkable event occurred in the Imhotep region where a particular location underwent localised erosion reaching $\sim 4$ meters vertically (El-Maarry et al. 2017, Fig. 18). This intensive erosion resulted in the exhumation of previously covered circular structures and boulders (El-Maarry et al. 2017). The extent of vertical erosion in Imhotep appears to be consistent with what was observed in Anubis. In addition, the scarp retreats in Anubis and Hapi were observed to initiate with brightening of receding scarps, which would indicate the exposure of water ice (El-Maarry et al. 2017), which along with the consistent depth (4-5 m in Anubis and Imhotep) may indicate the presence a certain thermophysical boundary on the vertical extent of this type of erosion.

\subsection{Circular Features and Possible Role of Impacts}

Impact cratering is one of the fundamental geologic processes that act on planetary bodies. A discussion of the possible role of impacts/collisions in forming comet 67P (e.g., Jutzi and Asphaug 2015; Jutzi and Benz 2017; Rickman et al. 2015) is beyond the scope of this chapter as we merely discuss here surface features that might be impact-related. Circular depressions are a common morphological feature on solid surfaces. Comets are no exception and all nuclei visited by space missions have displayed crater-like features. On planets and asteroids, the large majority of circular depressions results from impacts (except for bodies that are large, and internally hot enough, to drive volcanism), and these craters reflect the collisional history of the body. On objects where active erosion takes place, some of these depressions can be associated to the formation of subterranean cavities and subsequent collapse.

Prior to Rosetta, Vincent et al. (2015b) reviewed the observations of crater-like features on cometary nuclei. They found that these morphologies appear as two main types: pit-halo (circular pit surrounded by a shallow depression) and deep pits (flat-floor features circled by steep walls, no rim). Both types display talus close to the pit's walls, indicating of postformation wall collapse. The Rosetta mission returned similar observations and provided high resolution views of pits of ranging from a few meters to several hundred meters in 

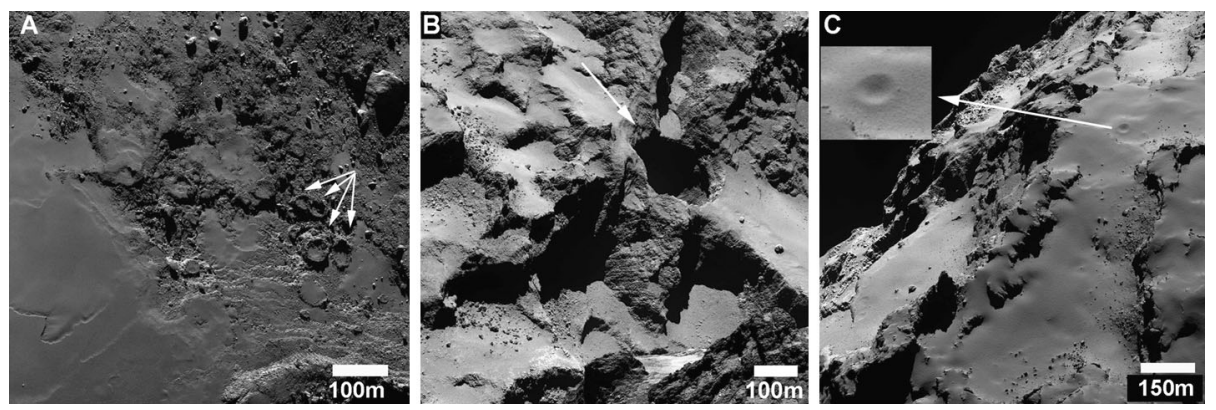

Fig. 19 Circular features on 67P. (A) Cluster of circular features in the Imhotep region. Note the patch of NCM to the southeast shown previously in Fig. 18 where additional circular features were exhumed. The apparent clustering of these features argues against an impact origin. (B) One of the circular pits first reported by Vincent et al. (2015b). Vincent et al. (2015b) argued against an impact origin for these pits and favored a sinkhole collapse-like mechanism. (C) A candidate impact feature first reported by Thomas et al. (2015b) that either impacted the NCM or was covered by it. All images were acquired in Sep. 2014 and are adapted from El-Maarry et al. (2015a)

diameter. A particular set of deep circular pits was reported by Vincent et al. (2015a). These pits varied in size but exhibited clustering, and depth/diameter ratios of $\sim 0.78$ and $\sim 0.26$ for active and inactive pits, respectively (Vincent et al. 2015b).

While circular depressions on comets are well characterized, their formation mechanism remains challenging to establish. The Deep Impact mission (A'Hearn et al. 2005) and modeling experiments (e.g., Vincent et al. 2015b) have shown that similar morphologies can be created by impacts. Yet, the size and apparent clustering of circular features suggests that alternative mechanisms play a role. The current population of small impactors potentially encountered by a Jupiter Family Comet on its orbit does not match the size frequency distribution (SFD) of observed depressions (Vincent et al. 2015b). It has been argued that erosion, being much faster on comets than other bodies due to the sublimation of a major component of the object, is responsible for enlarging the pits and thus modifying the SFD. This is not confirmed by observations. Only a handful of mass wasting events over one orbit of comet 67P has been observed by Rosetta, and no preexisting deep pits were observed to grow.

In short, comet 67P is devoid of unambiguous impact features. Currently, the best candidate is a $35 \mathrm{~m}$-wide bowl-shaped depression, which may have been covered by NCMs in the Ash region (Thomas et al. 2015b, Fig. 19). Any potentially new impacts would probably constitute micro-impacts primarily caused by the NCM back fall. However, these would be either too difficult to detect on consolidated materials, or would be promptly eroded away or covered by newly depositing NCMs.

\section{Forces Driving the Active Processes}

Having reviewed the setting and evolution of the numerous features on 67P, as well as the processes most likely to drive them, we briefly discuss here the main driving forces for the key processes that act on 67P specifically, and probably all active periodical comets in general. 


\subsection{Gravity and Shape Driven Internal Stresses}

Gravity on 67P, while only $\sim 10^{-5}$ of Earth's, plays a main role in controlling the distribution of mass-wasted events, as well as the placement of NCMs that are deposited from the coma on the northern hemisphere. In addition, 67P's irregular bi-lobed shape complicates its gravitational field and creates zones where internal stresses may cause tectonic events. For instance, a long (>500 m-long) fracture system is located in the northern neck region (and may even extend further below the NCM cover in the Hapi region, Fig. 11B). This fracture was observed to lengthen by tens of metres, in addition to the possible development of new parallel fractures (El-Maarry et al. 2017). Numerical models reported in Hirabayashi et al. (2016) suggested that outgassing on 67P would generate torques that affect the rotational period of the comet, and that 67P's shape should lead to a concentration of these stresses in the neck region to levels that may lead to splitting and re-merging of the lobes. Indeed, the timing of the neck fracture growth on 67P was consistent with the time when 67P's rotation period changed (El-Maarry et al. 2017). A recent study by Matonti et al. (2019) suggests that bilobate comets such as 67P are subjected to shear deformation caused by shape-driven stresses that could lead to the formation of shear-fracture and fault networks both on the surface and in its interior. The study further suggests that certain fractures and ridges in 67P's southern hemisphere, particularly in the Wosret (large lobe, e.g., Fig. 11C) and Sobek (southern neck) regions are indicative of such stresses.

\subsection{Seasonal Effects of Illumination and Orbital Configuration}

67P orbits the sun on an ellipse with a perihelion distance of 1.2432 au and an aphelion of 5.6824 au with an inclination of $7.0402^{\circ}$, typical for Jupiter Family comets. The rotation period on the approach leg to the Sun was $\sim 12.4 \mathrm{~h}$ decreasing in the vicinity of perihelion due to non-gravitational forces (Keller et al. 2015, see Sect. 4.3). The large obliquity of $52^{\circ}$ of the rotational axis of the nucleus combined with the close coincidence of the southern solstice with the perihelion passage leads to strongly varying seasonal insolation. Near perihelion, regions at high northern latitudes are not illuminated at all, while the total insolation of the comet reaches its maximum. This variation of the thermal input determines the seasonal activity pattern. The peculiar bi-lobate shape of $67 \mathrm{P}$ with a strong constriction between the lobes in the neck region (that forms a large concavity) strongly influences the diurnal insolation. Particularly near the north pole, the shadow of the steep and high rim wall of the small lobe (Fig. 20) is responsible for an additional interruption of the insolation during the day time of each rotation cycle. The polar day on southern latitudes of the nucleus near southern solstice and the extreme insolation changes caused by the wandering shadows provide an environment with strong thermal gradients and resulting stresses.

First estimates of the erosion by activity caused by water ice sublimation were calculated using a two-layer model by Keller et al. (2015) testing a range of different parameters. These models demonstrated that erosion averaged over the southern hemisphere was $\sim 15 \mathrm{~m}$ (Keller et al. 2015). These calculations highlighted the maximum capability of erosion by water ice sublimation. The models showed that the erosion in the southern hemisphere was about 4 times stronger than on the northern hemisphere. The erosion over one spin period ( 1 comet day) varied between a fraction of a millimeter on the northern hemisphere, when the comet was about 3 au away from the sun before perihelion, to several centimeters on the southern hemisphere around perihelion.

It should be noted that the models of Keller et al. (2015) assumed that the surface of the nucleus has homogeneous properties. The cometary activity creates torques that influence the rotation period of the nucleus. While it was possible to predict the variation of 
Fig. 20 Viewing factors of insolation model for 67P by Keller et al. (2015). This model shows the degree to which each single facet of the shape model is exposed to irradiation from other facets ( 0 implying none,

1 implying that the entire field of view of a facet is filled by other facets. Note that the concavity of the northern neck (arrow) affects insolation patterns greatly and results in excessive self-heating in the northern neck
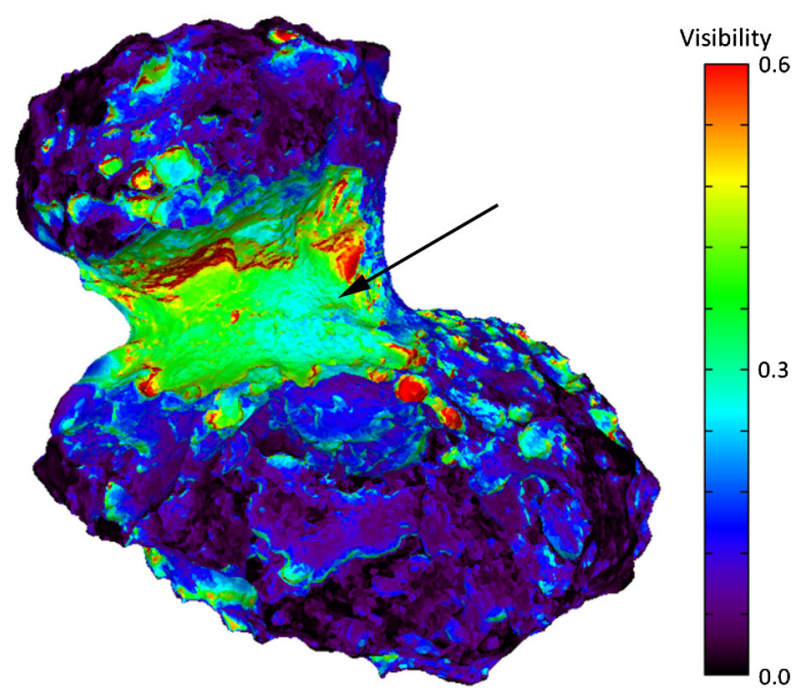

the rotation period over the perihelion passage (Keller et al. 2015) based on these simple models more thorough investigations showed that a fully homogeneous surface activity cannot explain all the details (Keller et al. 2017). The pronounced imbalance of the insolation, activity, and erosion between the south and the north hemispheres, and the observation that the northern hemisphere is widely covered by NCMs, suggests that mass is transferred from the south to the north. Observations with OSIRIS show that $\mathrm{cm}$ and $\mathrm{dm}$ sized particles are liberated from active surfaces on the south around perihelion (Fulle et al. 2016; Ott et al. 2017). The trajectories of some of these particles could be determined. At least $20 \%$ of them (and possibly more) return directly back to the nucleus surface (Agarwal et al. 2016; Keller et al. 2017). These chunks themselves show activity that leads to additional (nongravitational) acceleration in anti-solar direction towards the surface. Modelling work (e.g., Keller et al. 2017) indicates that ejected dust particles in the $\mathrm{cm}$ to $\mathrm{dm}$ size range would be volatile rich; predominantly water ice-rich due to the higher volatility of other species such $\mathrm{CO}_{2}$. The ability of the dust grains to retain water ice but not the more volatile $\mathrm{CO}$ or $\mathrm{CO}_{2}$ is consistent with the fact that $\mathrm{CO}$ and $\mathrm{CO}_{2}$ in 67P's coma were predominantly sourced from the southern hemisphere during the entire period of the Rosetta mission (Laeuter et al. 2018).

The northern neck region Hapi is in polar night during the perihelion passage. When the particles enter the seasonal shadow, they are "shock frozen" and maintain all their water ice content. This rapid freezing contributes to the exceptional activity level observed at Hapi when the comet returns from its aphelion, similar to what was observed early in the mission (e.g., Lara et al. 2015). If more than $25 \%$ of the lifted mass from the south falls back on the northern hemisphere, the back fall will accumulate orbit by orbit. In any case, the fall back in certain regions will accumulate because it cannot be removed entirely by the water sublimation-induced activity during northern summer.

In summary, the strong seasonal variation with an overwhelming activity level during southern summer near perihelion strongly influences the current evolution of the nucleus. Most of the erosion of the consolidated nucleus takes place on the south driven by water, $\mathrm{CO}_{2}$, and $\mathrm{CO}$ sublimation, which is consistent with the observed hemispherical dichotomy in surface morphology. 


\subsection{Insolation-Driven Thermal Stresses}

Cometary nuclei are subject to strong diurnal and seasonal surface and sub-surface temperature variations, which result from a combination of their elliptic orbit, fast rotation (i.e., few hours) (Lamy et al. 2004) and low thermal inertia (Groussin et al., this volume). In the case of 67P, these changes can be even more pronounced given its shape and orbit and how they affect the insolation patterns as discussed in Sect. 4.1. The distance of the comet to the Sun during its elliptical orbit also plays a major role. On a diurnal scale, temperature may vary by more than $200 \mathrm{~K}$ in a few hours during perihelion (El-Maarry et al. 2015a), and in regions with large projected shadows like Hapi, the temperature gradient can reach $30 \mathrm{~K} / \mathrm{min}$ (Ali-Lagoa et al. 2015). These large and rapid temperature variations could cause severe thermal stresses on cometary materials. Indeed, the strongest case is offered by the detection of polygonal networks on the surface of 67P (see Sect. 3.1.2). By analogy with similar morphologies found on the Earth and Mars, Auger et al. (2018) interpreted them as thermal contraction crack polygons, resulting from the thermal stress of hard icy materials located in the sub-surface. Near subsurface water ice is expected to expand and contract due to temperature variations, which are large and fast enough to cause thermal stress that exceed the tensile stress of the surface (e.g., Lachenbruch 1962).

The presence of a hard ( $\mathrm{MPa}$ ) layer of water ice below the surface is supported by Philae observations, laboratory experiments and modeling. For instance, Spohn et al. (2015) reported on the first results from the "Multi Purpose Sensors for Surface and Subsurface Science" (MUPUS) instrument on Philae, and concluded that the uniaxial compressive strength of the sub-surface material is larger than 2 MPa. Knapmeyer et al. (2018) utilized the Cometary Acoustic Surface Sounding Experiment (SESAME/CASSE) observations to infer the presence of a hard layer (Young's modulus $E$ of $7.2 \mathrm{MPa} \leq E \leq 980 \mathrm{MPa}$ ) located $10-50 \mathrm{~cm}$ below surface. These findings are consistent with a processed water ice layer of a few centimeters to decimeters thick, which results from the sublimation/redeposition and/or sintering of water ice close to the surface. This hardening process has been studied and demonstrated for comets, both experimentally (Jessberger and Kotthaus 1989; Pommerol et al. 2015a) and theoretically (Kossacki et al. 2015), and leads to typical strengths of $1 \mathrm{MPa}$, much harder than the nucleus bulk tensile strength of $<100 \mathrm{~Pa}$ (Groussin et al., this volume).

A complete thermo-mechanical model was developed by Attree et al. (2018) to study the stress induced by the diurnal temperature variations in such a hard water ice layer. The stress can reach tens of $\mathrm{MPa}$ in the first meter, exceeding the tensile strength of the processed icy layer at all latitudes, assuming a thermal inertia $>50 \mathrm{~J} \mathrm{~m}^{-2} \mathrm{~K}^{-1} \mathrm{~s}^{0.5}$ and an ice content $>45 \%$. These results agree with an older analysis made by Kuehrt and Keller (1994) with a less elaborated thermal model. All the above arguments support the formation of the observed polygonal networks by thermal stress.

While polygons are easily recognizable as surface morphologies resulting from thermal stress, there are not unique examples. Many fractures, observed at all scales on the nucleus (Sect. 3.2), may also be caused by thermal stress. Their identification is however difficult because a mechanical stress can also be the origin of these fractures. It is nevertheless likely that the fractures observed on boulders, at the meter scale, are of thermal stress origin, as suggested for boulders on the Moon and airless bodies in general (e.g., Molaro et al. 2017). On 67P, because of the low thermal inertia, boulders present a strong temperature gradient between the side facing the Sun and the opposite one, making them a perfect case for a strong thermal stress leading to fracturing and breakdown. Numerous fractured boulders have been observed on the surface (Fig. 21). 
Fig. 21 A fractured boulder in the Hatmehit region. The weathering of this boulder has probably been caused by thermal stresses

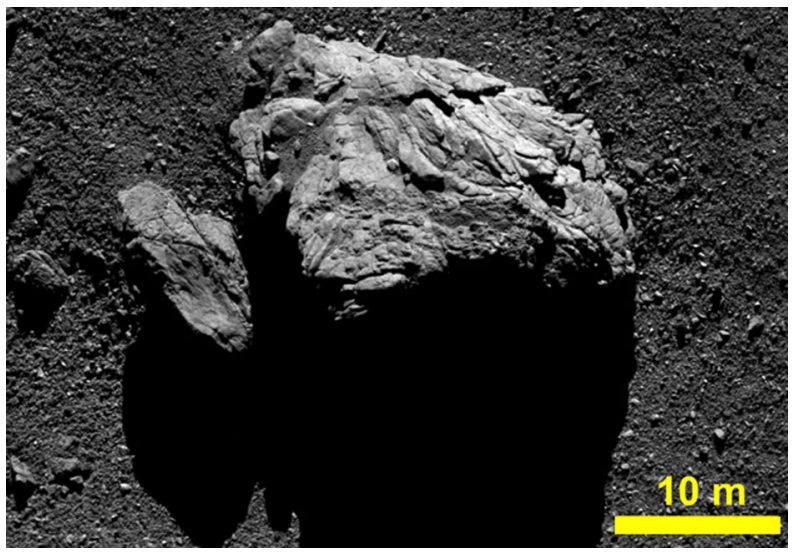

It is also highly probable that opening new fractures leads to activity/outgassing since it exposes fresh, icy materials to sunlight. A study by Skorov et al. (2016) suggests that if the new fractures are shallow $(<1 \mathrm{~m})$ and expose water ice, the increase in activity can be negligible compared to the global activity. On the contrary, if the new fractures are deep $(>1 \mathrm{~m})$ and expose highly volatiles species like $\mathrm{CO}$ or $\mathrm{CO}_{2}$ to sunlight, the increase in activity can be important, in the form of outbursts lasting for a few minutes to hours (Skorov et al. 2016).

\section{Concluding Remarks}

Historically, the term "activity" in cometary science has generally been associated with the outgassing events and the production of a coma (essentially what could be observable by Earth-based instruments). What space missions achieved, culminating with Rosetta, was to widen our perspective on the activity of comets. Rosetta in particular has demonstrated that when comets become active, they behave like a typical geologically active solar system body. Most of the processes and resulting morphological changes that have been discussed here occurred mainly when the comet was 2-3 a.u. away from the Sun, and preferentially in locations at or close to the sub-solar latitude (e.g., El-Maarry et al. 2017; Vincent et al. 2016). It is clear that solar insolation is the main energy input that feeds most of the activity. Its intensity directly controls the scale of erosion and outgassing activity that occurs (e.g., Keller et al. 2015, 2017), whereas its derivative/gradient (affected by distance from the sun and comet geometry) dictates the magnitude of thermal stresses that act to disintegrate consolidated materials through fracturing, followed by mass wasting (e.g., El-Maarry et al. 2015a; Pajola et al. 2017b).

With regards to cometary evolution, Belton (2010) had proposed an evolutionary sequence based on the diverse surface morphologies of visited comets where comets would evolve from a rougher Wild 2-type-like morphology to Tempel 1-like, predicting that Hartley 2 and 67P would exhibit surface morphologies similar to Tempel 1 . The diversity in terrain types observed at Hartley 2 and 67P showed that comet nucleus evolution follows a more complicated path. Cheng et al. (2013) proposed an alternative evolutionary sequence where geologic activity with diverse outcomes would be responsible for the different morphologies depending on the intensity of the process (specifically, vapor outflow) driving the 
activity. The global spatial and temporal coverage of Rosetta allowed us to gain more understating of cometary activity that is consistent with the general ideas proposed by both Belton (2010) and Cheng et al. (2013). Comet 67P shows diverse morphologies ranging from rough terrains and high cliffs to smooth and flat terrains. It also displays evidence for many active geological processes. As such, comets may be evolving in the same way that any active planetary body would: Outgassing and tectonic events act to roughen the surface whereas active erosion (including weathering and transport) progressively smoothens it, and it's the intensity of these processes that controls surface diversity. The flattening out of 67P's southern hemisphere where higher rates of erosion are taking place (Keller et al. 2017) and statistical analyses of cliff heights for comet 67P (Vincent et al. 2017) are consistent with this evolutionary view for $67 \mathrm{P}$, and probably all active comets in general.

Acknowledgements This project has received funding from the European Union's Horizon 2020 research and innovation programme under grant agreement No. 686709 (MiARD). This work was supported by the Swiss State Secretariat for Education, Research and Innovation (SERI) under contract number 16.0008-2. The opinions expressed and arguments employed herein do not necessarily reflect the official view of the Swiss Government.

Publisher's Note Springer Nature remains neutral with regard to jurisdictional claims in published maps and institutional affiliations.

Open Access This article is distributed under the terms of the Creative Commons Attribution 4.0 International License (http://creativecommons.org/licenses/by/4.0/), which permits unrestricted use, distribution, and reproduction in any medium, provided you give appropriate credit to the original author(s) and the source, provide a link to the Creative Commons license, and indicate if changes were made.

\section{References}

J. Agarwal, M.F. A'Hearn, J.-B. Vincent, C. Güttler, S. Höfner, H. Sierks, C. Tubiana, C. Barbieri, P.L. Lamy, R. Rodrigo, D. Koschny, H. Rickman, M.A. Barucci, J.-L. Bertaux, I. Bertini, S. Boudreault, G. Cremonese, V. Da Deppo, B. Davidsson, S. Debei, M. De Cecco, J. Deller, S. Fornasier, M. Fulle, A. Gicquel, O. Groussin, P.J. Gutiérrez, M. Hofmann, S.F. Hviid, W.-H. Ip, L. Jorda, H.U. Keller, J. Knollenberg, J.-R. Kramm, E. Kührt, M. Küppers, L.M. Lara, M. Lazzarin, J.J. Lopez Moreno, F. Marzari, G. Naletto, N. Oklay, X. Shi, N. Thomas, Mon. Not. R. Astron. Soc. 462, S78 (2016)

J. Agarwal, V. Della Corte, P.D. Feldman, B. Geiger, S. Merouane, I. Bertini, D. Bodewits, S. Fornasier, E. Grün, P. Hasselmann, M. Hilchenbach, S. Höfner, S. Ivanovski, L. Kolokolova, M. Pajola, A. Rotundi, H. Sierks, A.J. Steffl, N. Thomas, M.F. A'Hearn, C. Barbieri, M.A. Barucci, J.L. Bertaux, S. Boudreault, G. Cremonese, V. Da Deppo, B. Davidsson, S. Debei, M. De Cecco, J.F. Deller, L.M. Feaga, H. Fischer, M. Fulle, A. Gicquel, O. Groussin, C. Güttler, P.J. Gutiérrez, M. Hofmann, K. Hornung, S.F. Hviid, W.H. Ip, L. Jorda, H.U. Keller, J. Kissel, J. Knollenberg, A. Koch, D. Koschny, J.R. Kramm, E. Kührt, M. Küppers, P.L. Lamy, Y. Langevin, L.M. Lara, M. Lazzarin, Z.Y. Lin, J.J. Lopez Moreno, S.C. Lowry, F. Marzari, S. Mottola, G. Naletto, N. Oklay, J.Wm. Parker, R. Rodrigo, J. Rynö, X. Shi, O. Stenzel, C. Tubiana, J.B. Vincent, H.A. Weaver, B. Zaprudin, Mon. Not. R. Astron. Soc. 469, S606 (2017)

M.F. A’Hearn, M.J.S. Belton, W.A. Delamere, J. Kissel, K.P. Klaasen, L.A. McFadden, K.J. Meech, H.J. Melosh, P.H. Schultz, J.M. Sunshine, P.C. Thomas, J. Veverka, D.K. Yeomans, M.W. Baca, I. Busko, C.J. Crockett, S.M. Collins, M. Desnoyer, C.A. Eberhardy, C.M. Ernst, T.L. Farnham, L. Feaga, O. Groussin, D. Hampton, S.I. Ipatov, J-.Y. Li, D. Lindler, C.M. Lisse, N. Mastrodemos, W.M. Owen, J.E. Richardson, D.D. Wellnitz, R.L. White, Science 310, 258 (2005)

M.F. A'Hearn, M.J.S. Belton, W.A. Delamere, L.M. Feaga, D. Hampton, J. Kissel, K.P. Klaasen, L.A. McFadden, K.J. Meech, H. Jay Melosh, P.H. Schultz, J.M. Sunshine, P.C. Thomas, J. Veverka, D.D. Wellnitz, D.K. Yeomans, S. Besse, D. Bodewits, T.J. Bowling, B.T. Carcich, S.M. Collins, T.L. Farnham, O. Groussin, B. Hermalyn, M.S. Kelley, J.Y. Li, D.J. Lindler, C.M. Lisse, S.A. McLaughlin, F. Merlin, S. Protopapa, J.E. Richardson, J.L. Williams, Science (80-) 332, 1396 (2011)

V. Alí-Lagoa, M. Delbo', G. Libourel, Astrophys. J. Lett. 810, L22 (2015)

N. Attree, O. Groussin, L. Jorda, Astron. Astrophys. 610, 76 (2018) 
A.-T. Auger, O. Groussin, L. Jorda, S. Bouley, R. Gaskell, P.L. Lamy, C. Capanna, N. Thomas, A. Pommerol, H. Sierks, C. Barbieri, R. Rodrigo, D. Koschny, H. Rickman, H.U. Keller, J. Agarwal, M.F. A'Hearn, M.A. Barucci, J.-L. Bertaux, I. Bertini, G. Cremonese, V. Da Deppo, B.J.R. Davidsson, S. Debei, M. De Cecco, M.R. El-Maarry, S. Fornasier, M. Fulle, P.J. Gutiérrez, C. Güttler, S.F. Hviid, W.-H. Ip, J. Knollenberg, J.-R. Kramm, E. Kührt, M. Küppers, F. La Forgia, L.M. Lara, M. Lazzarin, J.J. Lopez Moreno, S. Marchi, F. Marzari, M. Massironi, H. Michalik, G. Naletto, N. Oklay, M. Pajola, L. Sabau, C. Tubiana, J.-B. Vincent, K.-P. Wenzel, Astron. Astrophys. 583, A35 (2015)

A.-T. Auger, O. Groussin, L. Jorda, M.R. El-Maarry, S. Bouley, A. Séjourné, R. Gaskell, C. Capanna, B. Davidsson, S. Marchi, S. Höfner, P.L. Lamy, H. Sierks, C. Barbieri, R. Rodrigo, D. Koschny, H. Rickman, H.U. Keller, J. Agarwal, M.F. A’Hearn, M.A. Barucci, J.-L. Bertaux, I. Bertini, G. Cremonese, V. Da Deppo, S. Debei, M. De Cecco, S. Fornasier, M. Fulle, P.J. Gutiérrez, C. Güttler, S. Hviid, W.-H. Ip, J. Knollenberg, J.-R. Kramm, E. Kührt, M. Küppers, L.M. Lara, M. Lazzarin, J.J. Lopez Moreno, F. Marzari, M. Massironi, H. Michalik, G. Naletto, N. Oklay, A. Pommerol, L. Sabau, N. Thomas, C. Tubiana, J.-B. Vincent, K.-P. Wenzel, Icarus 301, 173 (2018)

A.T. Basilevsky, S.S. Krasilnikov, U. Mall, S.F.S. Hviid, Y.V. Skorov, H.U. Keller, Planet. Space Sci. 140, 80 (2017)

M.J.S. Belton, Icarus 210, 881 (2010)

J. Bennet, M. Donahue, N. Schneider, M. Voit, The Cosmic Perspective, 8th edn. (2017). Pearson

J. Bertaux, Astron. Astrophys. 38, 1 (2015)

J.P. Bibring, Y. Langevin, J. Carter, P. Eng, B. Gondet, L. Jorda, S. Le Mouélic, S. Mottola, C. Pilorget, F. Poulet, M. Vincendon, Science (80-) 349, 8 (2015)

S.P.D. Birch, Y. Tang, A.G. Hayes, R.L. Kirk, D. Bodewits, H. Campins, Y. Fernandez, R. de Freitas Bart, N.W. Kutsop, H. Sierks, J.M. Soderblom, S.W. Squyres, J.-B. Vincent, Mon. Not. R. Astron. Soc. 469, S50 (2017)

D.E. Brownlee, F. Horz, R.L. Newburn, M. Zolensky, T.C. Duxbury, S. Sandford, Z. Sekanina, P. Tsou, M.S. Hanner, B.C. Clark, S.F. Green, J. Kissel, Science (80-) 304, 1764 (2004)

M. Bruck Syal, P.H. Schultz, J.M. Sunshine, M.F. A'Hearn, T.L. Farnham, D.S.P. Dearborn, Icarus 222, 610 (2013)

A.F. Cheng, C.M. Lisse, M. A'Hearn, Icarus 222, 808 (2013)

J.D.P. Deshapriya, M.A. Barucci, S. Fornasier, C. Feller, P.H. Hasselmann, H. Sierks, M.R. El-Maarry, M. Pajola, C. Barbieri, P.L. Lamy, R. Rodrigo, D. Koschny, H. Rickman, J. Agarwal, M.F. A'Hearn, J.L. Bertaux, I. Bertini, S. Boudreault, G. Cremonese, V. Da Deppo, B.J.R. Davidsson, S. Debei, J. Deller, M. De Cecco, M. Fulle, A. Gicquel, O. Groussin, P.J. Gutierrez, C. Güttler, M. Hofmann, S.F. Hviid, W. Ip, L. Jorda, H.U. Keller, J. Knollenberg, R. Kramm, E. Kührt, M. Küppers, L. Lara, M. Lazzarin, J.J. Lopez Moreno, F. Marzari, S. Mottola, G. Naletto, N. Oklay, D. Perna, A. Pommerol, N. Thomas, C. Tubiana, J.B. Vincent, Mon. Not. R. Astron. Soc. 462, S274 (2016)

M.R. El-Maarry, N. Thomas, A. Gracia-Berná, R. Marschall, A.-T. Auger, O. Groussin, S. Mottola, M. Pajola, M. Massironi, S. Marchi, S. Höfner, F. Preusker, F. Scholten, L. Jorda, E. Kührt, H.U. Keller, H. Sierks, M.F. A'Hearn, C. Barbieri, M.A. Barucci, J.-L. Bertaux, I. Bertini, G. Cremonese, V. Da Deppo, B. Davidsson, S. Debei, M. De Cecco, J. Deller, C. Güttler, S. Fornasier, M. Fulle, P.J. Gutierrez, M. Hofmann, S.F. Hviid, W.-H. Ip, J. Knollenberg, D. Koschny, G. Kovacs, J.-R. Kramm, M. Küppers, P.L. Lamy, L.M. Lara, M. Lazzarin, J.J. Lopez Moreno, F. Marzari, H. Michalik, G. Naletto, N. Oklay, A. Pommerol, H. Rickman, R. Rodrigo, C. Tubiana, J.-B. Vincent, Geophys. Res. Lett. 42, 5170 (2015a)

M.R. El-Maarry, N. Thomas, L. Giacomini, M. Massironi, M. Pajola, R. Marschall, A. Gracia-Berná, H. Sierks, C. Barbieri, P.L. Lamy, R. Rodrigo, H. Rickman, D. Koschny, H.U. Keller, J. Agarwal, M.F. A'Hearn, A.T. Auger, M.A. Barucci, J.-L. Bertaux, I. Bertini, S. Besse, D. Bodewits, G. Cremonese, V. Da Deppo, B. Davidsson, M. De Cecco, S. Debei, C. Güttler, S. Fornasier, M. Fulle, O. Groussin, P.J. Gutiérrez, S.F. Hviid, W.-H. Ip, L. Jorda, J. Knollenberg, G. Kovacs, J.R. Kramm, E. Kuhrt, M. Küppers, F. La Forgia, L.M. Lara, M. Lazzarin, J.J. Lopez Moreno, S. Marchi, F. Marzari, H. Michalik, G. Naletto, N. Oklay, A. Pommerol, F. Preusker, F. Scholten, C. Tubiana, J.B. Vincent, Astron. Astrophys. 583, A26 (2015b)

M.R. El-Maarry, N. Thomas, M. Pajola, M. Massironi, H. Sierks, C. Barbieri, P.L. Lamy, Astron. Astrophys. 593, A110 (2016)

M.R. El-Maarry, O. Groussin, N. Thomas, M. Pajola, A.T. Auger, B. Davidsson, X. Hu, S.F. Hviid, J. Knollenberg, C. Güttler, C. Tubiana, S. Fornasier, C. Feller, P. Hasselmann, J.B. Vincent, H. Sierks, C. Barbieri, P. Lamy, R. Rodrigo, D. Koschny, H.U. Keller, H. Rickman, M.F. A'Hearn, M.A. Barucci, J.L. Bertaux, I. Bertini, S. Besse, D. Bodewits, G. Cremonese, V. Da Deppo, S. Debei, M. De Cecco, J. Deller, J.D.P. Deshapriya, M. Fulle, P.J. Gutierrez, M. Hofmann, W.H. Ip, L. Jorda, G. Kovacs, J.R. Kramm, E. Kührt, M. Küppers, L.M. Lara, M. Lazzarin, Z. Yi Lin, J.J. Lopez Moreno, S. Marchi, F. Marzari, S. Mottola, G. Naletto, N. Oklay, A. Pommerol, F. Preusker, F. Scholten, X. Shi, Science (80-) 355, 1392 (2017) 
J.M. Ellwood, P.D. Evans, I.G. Wilson, J. Sediment. Res. 45, 554 (1975)

M. Fulle, F. Marzari, V. Della Corte, S. Fornasier, H. Sierks, A. Rotundi, C. Barbieri, P.L. Lamy, R. Rodrigo, D. Koschny, H. Rickman, H.U. Keller, J.J. López-Moreno, M. Accolla, J. Agarwal, M.F. A’Hearn, N. Altobelli, M.A. Barucci, J.-L. Bertaux, I. Bertini, D. Bodewits, E. Bussoletti, L. Colangeli, M. Cosi, G. Cremonese, J.-F. Crifo, V. Da Deppo, B. Davidsson, S. Debei, M. De Cecco, F. Esposito, M. Ferrari, F. Giovane, B. Gustafson, S.F. Green, O. Groussin, E. Grün, P. Gutierrez, C. Güttler, M.L. Herranz, S.F. Hviid, W. Ip, S.L. Ivanovski, J.M. Jerónimo, L. Jorda, J. Knollenberg, R. Kramm, E. Kührt, M. Küppers, L. Lara, M. Lazzarin, M.R. Leese, A.C. López-Jiménez, F. Lucarelli, E. Mazzotta Epifani, J.A.M. McDonnell, V. Mennella, A. Molina, R. Morales, F. Moreno, S. Mottola, G. Naletto, N. Oklay, J.L. Ortiz, E. Palomba, P. Palumbo, J.-M. Perrin, F.J.M. Rietmeijer, J. Rodríguez, R. Sordini, N. Thomas, C. Tubiana, J.-B. Vincent, P. Weissman, K.-P. Wenzel, V. Zakharov, J.C. Zarnecki, Astrophys. J. 821, 19 (2016)

L. Giacomini, M. Massironi, M.R. El-Maarry, L. Penasa, M. Pajola, N. Thomas, S.C. Lowry, C. Barbieri, G. Cremonese, F. Ferri, G. Naletto, I. Bertini, F. La Forgia, M. Lazzarin, F. Marzari, H. Sierks, P.L. Lamy, R. Rodrigo, H. Rickman, D. Koschny, H.U. Keller, J. Agarwal, M.F. A'Hearn, A.T. Auger, M.A. Barucci, J.L. Bertaux, S. Besse, D. Bodewits, V. Da Deppo, B. Davidsson, M. De Cecco, S. Debei, S. Fornasier, M. Fulle, O. Groussin, P.J. Gutierrez, C. Güttler, S.F. Hviid, W.H. Ip, L. Jorda, J. Knollenberg, G. Kovacs, J.R. Kramm, E. Kührt, M. Küppers, L.M. Lara, J.J. Lopez Moreno, S. Magrin, H. Michalik, N. Oklay, A. Pommerol, F. Preusker, F. Scholten, C. Tubiana, J.B. Vincent, Mon. Not. R. Astron. Soc. 462, S352 (2016)

O. Groussin, H. Sierks, C. Barbieri, P. Lamy, R. Rodrigo, D. Koschny, H. Rickman, H.U. Keller, M.F. A'Hearn, A.-T. Auger, M.A. Barucci, J.-L. Bertaux, I. Bertini, S. Besse, G. Cremonese, V. Da Deppo, B. Davidsson, S. Debei, M. De Cecco, M.R. El-Maarry, S. Fornasier, M. Fulle, P.J. Gutiérrez, C. Güttler, S. Hviid, W.-H. Ip, L. Jorda, J. Knollenberg, G. Kovacs, J.R. Kramm, E. Kührt, M. Küppers, L.M. Lara, M. Lazzarin, J.J. Lopez Moreno, S. Lowry, S. Marchi, F. Marzari, M. Massironi, S. Mottola, G. Naletto, N. Oklay, M. Pajola, A. Pommerol, N. Thomas, I. Toth, C. Tubiana, J.-B. Vincent, Astron. Astrophys. 583, A36 (2015)

E. Grün, J. Gebhard, A. Bar-Nun, J. Benkhoff, H. Düren, G. Eich, R. Hische, W.F. Huebner, H.U. Keller, G. Klees, H. Kochan, G. Kölzer, H. Kroker, E. Kührt, P. Lämmerzahl, E. Lorenz, W.J. Markiewicz, D. Möhlmann, A. Oehler, J. Scholz, K.J. Seidensticker, K. Roessler, G. Schwehm, G. Steiner, K. Thiel, H. Thomas, J. Geophys. Res. 98, 15091 (1993)

M. Hirabayashi, D.J. Scheeres, S.R. Chesley, S. Marchi, J.W. McMahon, J. Steckloff, S. Mottola, S.P. Naidu, T. Bowling, Nature 534, 352 (2016)

X. Hu, X. Shi, H. Sierks, M. Fulle, J. Blum, H.U. Keller, E. Kührt, B. Davidsson, C. Güttler, B. Gundlach, M. Pajola, D. Bodewits, J.-B. Vincent, N. Oklay, M. Massironi, S. Fornasier, C. Tubiana, O. Groussin, S. Boudreault, S. Höfner, S. Mottola, C. Barbieri, P.L. Lamy, R. Rodrigo, D. Koschny, H. Rickman, M. A'Hearn, J. Agarwal, M.A. Barucci, J.-L. Bertaux, I. Bertini, G. Cremonese, V. Da Deppo, S. Debei, M. De Cecco, J. Deller, M.R. El-Maarry, A. Gicquel, P. Gutierrez-Marques, P.J. Gutiérrez, M. Hofmann, S.F. Hviid, W.-H. Ip, L. Jorda, J. Knollenberg, G. Kovacs, J.-R. Kramm, M. Küppers, L.M. Lara, M. Lazzarin, J.J. Lopez-Moreno, F. Marzari, G. Naletto, N. Thomas, Astron. Astrophys. 604, A114 (2017)

H.L. Jessberger, M. Kotthaus, in Phys. Mech. Cometary Mater, ed. by J.J. Hunt, T.D. Guyenne (1989), pp. $141-146$

P. Jia, B. Andreotti, P. Claudin, Proc. Natl. Acad. Sci. 114, 2509 (2017)

L. Jorda, R. Gaskell, C. Capanna, S. Hviid, P. Lamy, J. Durech, G. Faury, O. Groussin, P. Gutiérrez, C. Jackman, S.J. Keihm, H.U. Keller, J. Knollenberg, E. Kührt, S. Marchi, S. Mottola, E. Palmer, F.P. Schloerb, H. Sierks, J.B. Vincent, M.F. A'Hearn, C. Barbieri, R. Rodrigo, D. Koschny, H. Rickman, M.A. Barucci, J.L. Bertaux, I. Bertini, G. Cremonese, V. Da Deppo, B. Davidsson, S. Debei, M. De Cecco, S. Fornasier, M. Fulle, C. Güttler, W.H. Ip, J.R. Kramm, M. Küppers, L.M. Lara, M. Lazzarin, J.J. Lopez Moreno, F. Marzari, G. Naletto, N. Oklay, N. Thomas, C. Tubiana, K.P. Wenzel, Icarus 277, 257 (2016)

M. Jutzi, E. Asphaug, Science (80-) 348, 1355 (2015)

M. Jutzi, W. Benz, Astron. Astrophys. 597, A62 (2017)

H.U. Keller, W.J. Markiewicz, Geophys. Res. Lett. 18, 249 (1991)

H.U. Keller, C. Arpigny, C. Barbieri, R.M. Bonnet, S. Cazes, M. Coradini, C.B. Cosmovici, W.A. Delamere, W.F. Huebner, D.W. Hughes, C. Jamar, D. Malaise, H.J. Reitsema, H.U. Schmidt, W.K.H. Schmidt, P. Seige, F.L. Whipple, K. Wilhelm, Nature 321, 320 (1986)

H.U. Keller, C. Barbieri, P. Lamy, H. Rickman, R. Rodrigo, K.-P. Wenzel, H. Sierks, M.F. A'Hearn, F. Angrilli, M. Angulo, M.E. Bailey, P. Barthol, M.A. Barucci, J.-L. Bertaux, G. Bianchini, J.-L. Boit, V. Brown, J.A. Burns, I. Büttner, J.M. Castro, G. Cremonese, W. Curdt, V. Da Deppo, S. Debei, M. De Cecco, K. Dohlen, S. Fornasier, M. Fulle, D. Germerott, F. Gliem, G.P. Guizzo, S.F. Hviid, W.-H. Ip, L. 
Jorda, D. Koschny, J.R. Kramm, E. Kührt, M. Küppers, L.M. Lara, A. Llebaria, A. López, A. LópezJimenez, J. López-Moreno, R. Meller, H. Michalik, M.D. Michelena, R. Müller, G. Naletto, A. Origné, G. Parzianello, M. Pertile, C. Quintana, R. Ragazzoni, P. Ramous, K.-U. Reiche, M. Reina, J. Rodríguez, G. Rousset, L. Sabau, A. Sanz, J.-P. Sivan, K. Stöckner, J. Tabero, U. Telljohann, N. Thomas, V. Timon, G. Tomasch, T. Wittrock, M. Zaccariotto, Space Sci. Rev. 128, 433 (2007)

H.U. Keller, S. Mottola, B. Davidsson, S.E. Schröder, Y. Skorov, E. Kührt, O. Groussin, M. Pajola, S.F. Hviid, F. Preusker, F. Scholten, M.F. A’Hearn, H. Sierks, C. Barbieri, P. Lamy, R. Rodrigo, D. Koschny, H. Rickman, M.A. Barucci, J.-L. Bertaux, I. Bertini, G. Cremonese, V. Da Deppo, S. Debei, M. De Cecco, S. Fornasier, M. Fulle, P.J. Gutiérrez, W.-H. Ip, L. Jorda, J. Knollenberg, J.R. Kramm, M. Küppers, L.M. Lara, M. Lazzarin, J.J. Lopez Moreno, F. Marzari, H. Michalik, G. Naletto, L. Sabau, N. Thomas, J.-B. Vincent, K.-P. Wenzel, J. Agarwal, C. Güttler, N. Oklay, C. Tubiana, Astron. Astrophys. 583, A34 (2015)

H.U. Keller, S. Mottola, S.F. Hviid, J. Agarwal, E. Kührt, Y. Skorov, K. Otto, J.B. Vincent, N. Oklay, S.E. Schröder, B. Davidsson, M. Pajola, X. Shi, D. Bodewits, I. Toth, F. Preusker, F. Scholten, H. Sierks, C. Barbieri, P. Lamy, R. Rodrigo, D. Koschny, H. Rickman, M.F. A’Hearn, M.A. Barucci, J.L. Bertaux, I. Bertini, G. Cremonese, V. Da Deppo, S. Debei, M. De Cecco, J. Deller, S. Fornasier, M. Fulle, O. Groussin, P.J. Gutiérrez, C. Güttler, M. Hofmann, W.H. Ip, L. Jorda, J. Knollenberg, J.R. Kramm, M. Küppers, L.M. Lara, M. Lazzarin, J.J. Lopez-Moreno, F. Marzari, G. Naletto, C. Tubiana, N. Thomas, Mon. Not. R. Astron. Soc. 469, S357 (2017)

M. Knapmeyer, H.-H. Fischer, J. Knollenberg, K.J. Seidensticker, K. Thiel, W. Arnold, C. Faber, D. Möhlmann, Icarus 310, 165-193 (2018)

H. Kochan, B. Feuerbacher, F. Joo, J. Klinger, W. Seboldt, A. Bischoff, H. Duren, D. Stoffler, T. Spohn, H. Fechtig, E. Grun, H. Kohl, D. Krankowsky, K. Roessler, K. Thiel, G. Schwehm, U. Weishaupt, Adv. Space Res. 9, 113 (1989)

N.I. Kömle, G. Kargl, K. Thiel, K. Seiferlin, Planet. Space Sci. 44, 675 (1996)

K.J. Kossacki, N.I. Kömle, J. Leliwa-Kopystyński, G. Kargl, Icarus 128, 127 (1997)

K.J. Kossacki, S.Ł. Szutowicz, J. Leliwa-Kopystyński, Icarus 142, 202-218 (1999)

K.J. Kossacki, T. Spohn, A. Hagermann, E. Kaufmann, E. Kührt, Icarus 260, 464 (2015)

E. Kuehrt, H.U. Keller, Icarus 109, 121 (1994)

F. La Forgia, L. Giacomini, M. Lazzarin, M. Massironi, N. Oklay, F. Scholten, M. Pajola, I. Bertini, G. Cremonese, C. Barbieri, G. Naletto, E. Simioni, F. Preusker, N. Thomas, H. Sierks, P. Lamy, R. Rodrigo, D. Koschny, H. Rickman, H.U. Keller, J. Agarwal, A.-T. Auger, M.F. A'Hearn, M.A. Barucci, J.-L. Bertaux, S. Besse, D. Bodewits, V. Da Deppo, B. Davidsson, S. Debei, M. De Cecco, M.R. El-Maarry, F. Ferri, S. Fornasier, M. Fulle, O. Groussin, P.J. Gutiérrez, C. Güttler, I. Hall, S.F. Hviid, W.-H. Ip, L. Jorda, J. Knollenberg, J.R. Kramm, E. Kührt, M. Küppers, L.-M. Lara, J.J. Lopez Moreno, S. Magrin, F. Marzari, H. Michalik, S. Mottola, A. Pommerol, C. Tubiana, J.-B. Vincent, Astron. Astrophys. 583, A41 (2015)

A.H. Lachenbruch, in Mech. Therm. Contract. Cracks Ice-Wedge Polyg. Permafr., ed. by A.H. Lachenbruch (Geol. Soc. Am., Boulder, 1962)

M. Laeuter, T. Kramer, M. Rubin, K. Altwegg, Mon. Not. R. Astron. Soc. 483, S852 (2018)

P.L. Lamy, I. Toth, Y.R. Fernandez, H.A. Weaver, in Comets II, ed. by M.C. Festou, H.U. Keller, H.A. Weaver (Univ. Arizona Press, Tucson, 2004), pp. 223-264

L.M. Lara, S. Lowry, J.-B. Vincent, P.J. Gutiérrez, A. Rożek, F. La Forgia, N. Oklay, H. Sierks, C. Barbieri, P.L. Lamy, R. Rodrigo, D. Koschny, H. Rickman, H.U. Keller, J. Agarwal, A.-T. Auger, M.F. A'Hearn, M.A. Barucci, J.-L. Bertaux, I. Bertini, S. Besse, D. Bodewits, G. Cremonese, B. Davidsson, V. Da Deppo, S. Debei, M. De Cecco, M.R. El-Maarry, F. Ferri, S. Fornasier, M. Fulle, O. Groussin, P. Gutié rrez-Marques, C. Güttler, S.F. Hviid, W.-H. Ip, L. Jorda, J. Knollenberg, G. Kovacs, J.-R. Kramm, E. Kührt, M. Küppers, M. Lazzarin, Z.-Y. Lin, J.J. López-Moreno, S. Magrin, F. Marzari, H. Michalik, R. Moissl-Fraund, F. Moreno, S. Mottola, G. Naletto, M. Pajola, A. Pommerol, N. Thomas, M.D. Sabau, C. Tubiana, Astron. Astrophys. 583, A9 (2015)

J.C. Lee, M. Massironi, W.H. Ip, L. Giacomini, S. Ferrari, L. Penasa, M.R. El-Maarry, M. Pajola, I.L. Lai, Z.Y. Lin, F. Ferri, H. Sierks, C. Barbieri, P. Lamy, R. Rodrigo, D. Koschny, H. Rickman, H.U. Keller, J. Agarwal, M.F. A’Hearn, M.A. Barucci, J.L. Bertaux, I. Bertini, G. Cremonese, V. Da Deppo, B. Davidsson, S. Debei, M. De Cecco, J. Deller, S. Fornasier, M. Fulle, O. Groussin, P.J. Gutiérrez, C. Güttler, M. Hofmann, S.F. Hviid, L. Jorda, J. Knollenberg, G. Kovacs, J.R. Kramm, E. Kührt, M. Küppers, L.M. Lara, M. Lazzarin, F. Marzari, J.J. Lopez Moreno, G. Naletto, N. Oklay, X. Shi, N. Thomas, C. Tubiana, J.B. Vincent, Mon. Not. R. Astron. Soc. 462, S573 (2016)

A. Lethuillier, A. Le Gall, M. Hamelin, W. Schmidt, K.J. Seidensticker, R. Grard, V. Ciarletti, S. CaujolleBert, H.-H. Fischer, R. Trautner, Astron. Astrophys. 591, A32 (2016) 
M. Massironi, E. Simioni, F. Marzari, G. Cremonese, L. Giacomini, M. Pajola, L. Jorda, G. Naletto, S. Lowry, M.R. El-Maarry, F. Preusker, F. Scholten, H. Sierks, C. Barbieri, P. Lamy, R. Rodrigo, D. Koschny, H. Rickman, H.U. Keller, M.F. A’Hearn, J. Agarwal, A.-T. Auger, M.A. Barucci, J.-L. Bertaux, I. Bertini, S. Besse, D. Bodewits, C. Capanna, V. Da Deppo, B. Davidsson, S. Debei, M. De Cecco, F. Ferri, S. Fornasier, M. Fulle, R. Gaskell, O. Groussin, P.J. Gutiérrez, C. Güttler, S.F. Hviid, W.-H. Ip, J. Knollenberg, G. Kovacs, R. Kramm, E. Kührt, M. Küppers, F. La Forgia, L.M. Lara, M. Lazzarin, Z.-Y. Lin, J.J. Lopez Moreno, S. Magrin, H. Michalik, S. Mottola, N. Oklay, A. Pommerol, N. Thomas, C. Tubiana, J.-B. Vincent, Nature 526, 402 (2015)

C. Matonti, N. Attree, O. Groussin, L. Jorda, S. Viseur, S.F. Hviid, S. Bouley, D. Nébouy, A.-T. Auger, P.L. Lamy, H. Sierks, G. Naletto, R. Rodrigo, D. Koschny, B. Davidsson, M.A. Barucci, J.-L. Bertaux, I. Bertini, D. Bodewits, G. Cremonese, V. Da Deppo, S. Debei, M. De Cecco, J. Deller, S. Fornasier, M. Fulle, P.J. Gutiérrez, C. Güttler, W.-H. Ip, H.U. Keller, L.M. Lara, F. La Forgia, M. Lazzarin, A. Lucchetti, J.J. López-Moreno, F. Marzari, M. Massironi, S. Mottola, N. Oklay, M. Pajola, L. Penasa, F. Preusker, H. Rickman, F. Scholten, X. Shi, I. Toth, C. Tubiana, J.-B. Vincent, Nat. Geosci. 12, 157 (2019)

P. Migon, in Encyclopedia of Geomorphology, ed. by A.S. Goudie (Taylor \& Francis, London, 2004)

J.L. Molaro, S. Byrne, J.-L. Le, Icarus 294, 247 (2017)

S. Mottola, G. Arnold, H.-G. Grothues, R. Jaumann, H. Michaelis, G. Neukum, J.-P. Bibring, S.E. Schröder, M. Hamm, K.A. Otto, I. Pelivan, G. Proffe, F. Scholten, D. Tirsch, M. Kreslavsky, E. Remetean, F. Souvannavong, B. Dolives, Science (80-) 349, 2.232 (2015)

T. Ott, E. Drolshagen, D. Koschny, C. Güttler, C. Tubiana, E. Frattin, J. Agarwal, H. Sierks, I. Bertini, C. Barbieri, P.I. Lamy, R. Rodrigo, H. Rickman, M.F. A’Hearn, M.A. Barucci, J.-L. Bertaux, S. Boudreault, G. Cremonese, V. Da Deppo, B. Davidsson, S. Debei, M. De Cecco, J. Deller, C. Feller, S. Fornasier, M. Fulle, B. Geiger, A. Gicquel, O. Groussin, P.J. Gutiérrez, M. Hofmann, S.F. Hviid, W.-H. Ip, L. Jorda, H.U. Keller, J. Knollenberg, G. Kovacs, J.R. Kramm, E. Kührt, M. Küppers, L.M. Lara, M. Lazzarin, Z.Y. Lin, J.J. Ló pez-Moreno, F. Marzari, S. Mottola, G. Naletto, N. Oklay, M. Pajola, X. Shi, N. Thomas, J.-B. Vincent, B. Poppe, Mon. Not. R. Astron. Soc. 469, S276 (2017)

M. Pajola, J.-B. Vincent, C. Güttler, J.-C. Lee, I. Bertini, M. Massironi, E. Simioni, F. Marzari, L. Giacomini, A. Lucchetti, C. Barbieri, G. Cremonese, G. Naletto, A. Pommerol, M.R. El-Maarry, S. Besse, M. Küppers, F. La Forgia, M. Lazzarin, N. Thomas, A.-T. Auger, H. Sierks, P. Lamy, R. Rodrigo, D. Koschny, H. Rickman, H.U. Keller, J. Agarwal, M.F. A’Hearn, M.A. Barucci, J.-L. Bertaux, V. Da Deppo, B. Davidsson, M. De Cecco, S. Debei, F. Ferri, S. Fornasier, M. Fulle, O. Groussin, P.J. Gutierrez, S.F. Hviid, W.-H. Ip, L. Jorda, J. Knollenberg, J.-R. Kramm, E. Kürt, L.M. Lara, Z.-Y. Lin, J.J. Lopez Moreno, S. Magrin, S. Marchi, H. Michalik, R. Moissl, S. Mottola, N. Oklay, F. Preusker, F. Scholten, C. Tubiana, Astron. Astrophys. 583, A37 (2015)

M. Pajola, S. Mottola, M. Hamm, M. Fulle, B. Davidsson, C. Güttler, H. Sierks, G. Naletto, G. Arnold, H.-G. Grothues, R. Jaumann, H. Michaelis, J.P. Bibring, C. Barbieri, P.L. Lamy, R. Rodrigo, D. Koschny, H. Rickman, H.U. Keller, J. Agarwal, M.F. A’Hearn, M.A. Barucci, J.L. Bertaux, I. Bertini, S. Boudreault, G. Cremonese, V. Da Deppo, S. Debei, M. De Cecco, J. Deller, M.R. El Maarry, C. Feller, S. Fornasier, A. Gicquel, O. Groussin, P.J. Gutierrez, M. Hofmann, S.F. Hviid, W.H. Ip, L. Jorda, J. Knollenberg, J.R. Kramm, E. Kührt, M. Küppers, F. La Forgia, L.M. Lara, Z.Y. Lin, M. Lazzarin, J.J. Lopez Moreno, A. Lucchetti, F. Marzari, M. Massironi, H. Michalik, N. Oklay, A. Pommerol, F. Preusker, F. Scholten, N. Thomas, C. Tubiana, J.B. Vincent, Mon. Not. R. Astron. Soc. 462, S242-S252 (2016a)

M. Pajola, A. Lucchetti, J.-B. Vincent, N. Oklay, M.R. El-Maarry, I. Bertini, G. Naletto, M. Lazzarin, M. Massironi, H. Sierks, C. Barbieri, P. Lamy, R. Rodrigo, D. Koschny, H. Rickman, H.U. Keller, J. Agarwal, M.F. A'Hearn, M.A. Barucci, J.-L. Bertaux, S. Boudreault, G. Cremonese, V. Da Deppo, B. Davidsson, S. Debei, M. De Cecco, J. Deller, S. Fornasier, M. Fulle, A. Gicquel, O. Groussin, P.J. Gutierrez, C. Güttler, M. Hofmann, S. Höfner, S.F. Hviid, W.-H. Ip, L. Jorda, J. Knollenberg, J.-R. Kramm, E. Kührt, M. Küppers, F. La Forgia, L.M. Lara, J.-C. Lee, Z.-Y. Lin, J.J. Lopez Moreno, F. Marzari, H. Michalik, S. Mottola, F. Preusker, F. Scholten, N. Thomas, I. Toth, C. Tubiana, Astron. Astrophys. 592, L2 (2016b)

M. Pajola, N. Oklay, F. La Forgia, L. Giacomini, M. Massironi, I. Bertini, M.R. El-Maarry, F. Marzari, F. Preusker, F. Scholten, S. Höfner, J.-C. Lee, J.-B. Vincent, O. Groussin, G. Naletto, M. Lazzarin, C. Barbieri, H. Sierks, P. Lamy, R. Rodrigo, D. Koschny, H. Rickman, H.U. Keller, J. Agarwal, M.F. A'Hearn, M.A. Barucci, J.-L. Bertaux, G. Cremonese, V. Da Deppo, B. Davidsson, M. De Cecco, S. Debei, F. Ferri, S. Fornasier, M. Fulle, C. Güttler, P.J. Gutierrez, S.F. Hviid, W.-H. Ip, L. Jorda, J. Knollenberg, J.-R. Kramm, M. Küppers, E. Kürt, L.M. Lara, Z.-Y. Lin, J.J. Lopez Moreno, S. Magrin, H. Michalik, S. Mottola, N. Thomas, C. Tubiana, Astron. Astrophys. 592, A69 (2016c)

M. Pajola, A. Lucchetti, M. Fulle, S. Mottola, M. Hamm, V. Da Deppo, L. Penasa, G. Kovacs, M. Massironi, X. Shi, C. Tubiana, C. Güttler, N. Oklay, J.B. Vincent, I. Toth, B. Davidsson, G. Naletto, H. Sierks, C. Barbieri, P.L. Lamy, R.R.D. Koschny, H. Rickman, H.U. Keller, J. Agarwal, M.F. A'Hearn, M.A. 
Barucci, J.L. Bertaux, I. Bertini, G. Cremonese, S. Debei, M. De Cecco, J. Deller, M.R. El Maarry, S. Fornasier, E.F.A. Gicquel, O.G.P.J. Gutierrez, S. Höfner, M. Hofmann, S.F. Hviid, W.H. Ip, L. Jorda, J. Knollenberg, J.R. Kramm, E. Kührt, M. Küppers, L.M. Lara, M. Lazzarin, J.J. Lopez Moreno, F. Marzari, H. Michalik, F. Preusker, F. Scholten, N. Thomas, Mon. Not. R. Astron. Soc. 469, S636 (2017a)

M. Pajola, S. Höfner, J.B. Vincent, N. Oklay, F. Scholten, F. Preusker, S. Mottola, G. Naletto, S. Fornasier, S. Lowry, C. Feller, P.H. Hasselmann, C. Güttler, C. Tubiana, H. Sierks, C. Barbieri, P. Lamy, R. Rodrigo, D. Koschny, H. Rickman, H.U. Keller, J. Agarwal, M.F. A’Hearn, M.A. Barucci, J.-L. Bertaux, I. Bertini, S. Besse, S. Boudreault, G. Cremonese, V. da Deppo, B. Davidsson, S. Debei, M. de Cecco, J. Deller, J.D.P. Deshapriya, M.R. El-Maarry, S. Ferrari, F. Ferri, M. Fulle, O. Groussin, P. Gutierrez, M. Hofmann, S.F. Hviid, W.-H. Ip, L. Jorda, J. Knollenberg, G. Kovacs, J.R. Kramm, E. Kührt, M. Küppers, L.M. Lara, Z.-Y. Lin, M. Lazzarin, A. Lucchetti, J.J. Lopez Moreno, F. Marzari, M. Massironi, H. Michalik, L. Penasa, A. Pommerol, E. Simioni, N. Thomas, I. Toth, E. Baratti, Nat. Astron. 1, 92 (2017b)

M. Pätzold, T. Andert, M. Hahn, S.W. Asmar, J.P. Barriot, M.K. Bird, B. Häusler, K. Peter, S. Tellmann, E. Grün, P.R. Weissman, H. Sierks, L. Jorda, R. Gaskell, F. Preusker, F. Scholten, Nature 530, 63 (2016)

L. Penasa, M. Massironi, G. Naletto, E. Simioni, S. Ferrari, M. Pajola, A. Lucchetti, F. Preusker, F. Scholten, L. Jorda, R. Gaskell, F. Ferri, F. Marzari, B. Davidsson, S. Mottola, H. Sierks, C. Barbieri, P.L. Lamy, R. Rodrigo, D. Koschny, H. Rickman, H.U. Keller, J. Agarwal, M.F. A'Hearn, M.A. Barucci, J.L. Bertaux, I. Bertini, G. Cremonese, V. Da Deppo, S. Debei, M. De Cecco, J. Deller, C. Feller, S. Fornasier, E. Frattin, M. Fulle, O. Groussin, P.J. Gutierrez, C. Güttler, M. Hofmann, S.F. Hviid, W.H. Ip, J. Knollenberg, J.R. Kramm, E. Kührt, M. Küppers, F. La Forgia, L.M. Lara, M. Lazzarin, J.C. Lee, J.J. Lopez Moreno, N. Oklay, X. Shi, N. Thomas, C. Tubiana, J.B. Vincent, Mon. Not. R. Astron. Soc. 469, S741 (2017)

A. Pommerol, B. Jost, O. Poch, M.R. El-Maarry, B. Vuitel, N. Thomas, Planet. Space Sci. 109, 106 (2015a)

A. Pommerol, N. Thomas, M.R. El-Maarry, M. Pajola, O. Groussin, A.-T. Auger, N. Oklay, S. Fornasier, C. Feller, B. Davidsson, A. Gracia-Berná, B. Jost, R. Marschall, O. Poch, M.A. Barucci, J.-L. Bertaux, F. La Forgia, H.U. Keller, E. Kührt, S.C. Lowry, S. Mottola, G. Naletto, H. Sierks, C. Barbieri, P.L. Lamy, R. Rodrigo, D. Koschny, H. Rickman, J. Agarwal, M.F. A'Hearn, I. Bertini, S. Boudreault, G. Cremonese, V. Da Deppo, M. De Cecco, S. Debei, C. Güttler, M. Fulle, P.J. Gutierrez, S.F. Hviid, W.H. Ip, L. Jorda, J. Knollenberg, G. Kovacs, J.-R. Kramm, E. Küppers, L. Lara, M. Lazzarin, J.L. Lopez Moreno, F. Marzari, H. Michalik, F. Preusker, F. Scholten, C. Tubiana, J.-B. Vincent, Astron. Astrophys. 583, A25 (2015b)

F. Poulet, A. Lucchetti, J.-P. Bibring, J. Carter, B. Gondet, L. Jorda, Y. Langevin, C. Pilorget, C. Capanna, G. Cremonese, Mon. Not. R. Astron. Soc. 462, S23 (2016)

F. Preusker, F. Scholten, K.-D. Matz, T. Roatsch, K. Willner, S.F. Hviid, J. Knollenberg, L. Jorda, P.J. Gutiérrez, E. Kührt, S. Mottola, M.F. A’Hearn, N. Thomas, H. Sierks, C. Barbieri, P. Lamy, R. Rodrigo, D. Koschny, H. Rickman, H.U. Keller, J. Agarwal, M.A. Barucci, J.-L. Bertaux, I. Bertini, G. Cremonese, V. Da Deppo, B. Davidsson, S. Debei, M. De Cecco, S. Fornasier, M. Fulle, O. Groussin, C. Güttler, W.H. Ip, J.R. Kramm, M. Küppers, L.M. Lara, M. Lazzarin, J.J. Lopez Moreno, F. Marzari, H. Michalik, G. Naletto, N. Oklay, C. Tubiana, J.-B. Vincent, Astron. Astrophys. 583, A33 (2015)

F. Preusker, F. Scholten, K.-D. Matz, T. Roatsch, S.F. Hviid, S. Mottola, J. Knollenberg, E. Kührt, M. Pajola, N. Oklay, J.-B. Vincent, B. Davidsson, M.F. A'Hearn, J. Agarwal, C. Barbieri, M.A. Barucci, J.-L. Bertaux, I. Bertini, G. Cremonese, V. Da Deppo, S. Debei, M. De Cecco, S. Fornasier, M. Fulle, O. Groussin, P.J. Gutiérrez, C. Güttler, W.-H. Ip, L. Jorda, H.U. Keller, D. Koschny, J.R. Kramm, M. Küppers, P. Lamy, L.M. Lara, M. Lazzarin, J.J. Lopez Moreno, F. Marzari, M. Massironi, G. Naletto, H. Rickman, R. Rodrigo, H. Sierks, N. Thomas, C. Tubiana, Astron. Astrophys. 607, 1 (2017)

H. Rickman, S. Marchi, M.F. A’Hearn, C. Barbieri, M.R. El-Maarry, C. Güttler, W.-H. Ip, H.U. Keller, P. Lamy, F. Marzari, M. Massironi, G. Naletto, M. Pajola, H. Sierks, D. Koschny, R. Rodrigo, M.A. Barucci, J.-L. Bertaux, I. Bertini, G. Cremonese, V. Da Deppo, S. Debei, M. De Cecco, S. Fornasier, M. Fulle, O. Groussin, P.J. Gutiérrez, S.F. Hviid, L. Jorda, J. Knollenberg, J.-R. Kramm, E. Kührt, M. Küppers, L.M. Lara, M. Lazzarin, J.J. Lopez Moreno, H. Michalik, L. Sabau, N. Thomas, J.-B. Vincent, K.-P. Wenzel, Astron. Astrophys. 583, A44 (2015)

R.Z. Sagdeev, J. Blamont, A.A. Galeev, V.I. Moroz, V.D. Shapiro, V.I. Shevchenko, K. Szegó, Nature 321, 259 (1986)

D.W.G. Sears, H.W. Kochan, W.F. Huebner, Meteorit. Planet. Sci. 34, 497 (1999)

K. Seiferlin, T. Spobn, J. Benkbofp, Adv. Space Res. 15, 35 (1995)

X. Shi, X. Hu, H. Sierks, C. Güttler, M. A'Hearn, J. Blum, M.R. El-Maarry, E. Kührt, S. Mottola, M. Pajola, N. Oklay, S. Fornasier, C. Tubiana, H.U. Keller, J.-B. Vincent, D. Bodewits, S. Höfner, Z.-Y. Lin, A. Gicquel, M. Hofmann, C. Barbieri, P.L. Lamy, R. Rodrigo, D. Koschny, H. Rickman, M.A. Barucci, J.-L. Bertaux, I. Bertini, G. Cremonese, V. Da Deppo, B. Davidsson, S. Debei, M. De Cecco, M. Fulle, 
O. Groussin, P.J. Gutiérrez, S.F. Hviid, W.-H. Ip, L. Jorda, J. Knollenberg, G. Kovacs, J.-R. Kramm, M. Küppers, L.M. Lara, M. Lazzarin, J.J. Lopez-Moreno, F. Marzari, G. Naletto, N. Thomas, Astron. Astrophys. 586, A7 (2016)

Y.V. Skorov, L. Rezac, P. Hartogh, A.T. Bazilevsky, H.U. Keller, Astron. Astrophys. 593, A76 (2016)

A.L.A. Soderblom, T.L. Becker, G. Bennett, D.C. Boice, D.T. Britt, R.H. Brown, B.J. Buratti, C. Isbell, B. Giese, T. Hare, M.D. Hicks, R.L. Kirk, R.M. Nelson, J. Oberst, T.C. Owen, M.D. Rayman, B.R. Sandel, S.A. Stern, R.V. Yelle, Science (80-) 296, 1087 (2002)

T. Spohn, J. Knollenberg, A.J. Ball, M. Banaszkiewicz, J. Benkhoff, M. Grott, J. Grygorczuk, C. Hüttig, A. Hagermann, G. Kargl, E. Kaufmann, N. Kömle, E. Kührt, K.J. Kossacki, W. Marczewski, I. Pelivan, R. Schrödter, K. Seiferlin, Science (80-) 349, 2.464 (2015)

P.C. Thomas, J. Veverka, M.J.S. Belton, A. Hidy, M.F. A’Hearn, T.L. Farnham, O. Groussin, J.Y. Li, L.A. McFadden, J. Sunshine, D. Wellnitz, C. Lisse, P. Schultz, K.J. Meech, W.A. Delamere, Icarus 187, 4 (2007)

P. Thomas, M. A’Hearn, M.J.S. Belton, D. Brownlee, B. Carcich, B. Hermalyn, K. Klaasen, S. Sackett, P.H. Schultz, J. Veverka, S. Bhaskaran, D. Bodewits, S. Chesley, B. Clark, T. Farnham, O. Groussin, A. Harris, J. Kissel, J.Y. Li, K. Meech, J. Melosh, A. Quick, J. Richardson, J. Sunshine, D. Wellnitz, Icarus 222, 453 (2013a)

P.C. Thomas, M.F. A'Hearn, J. Veverka, M.J.S. Belton, J. Kissel, K.P. Klaasen, L.A. McFadden, H.J. Melosh, P.H. Schultz, S. Besse, B.T. Carcich, T.L. Farnham, O. Groussin, B. Hermalyn, J.Y. Li, D.J. Lindler, C.M. Lisse, K. Meech, J.E. Richardson, Icarus 222, 550 (2013b)

N. Thomas, B. Davidsson, M.R. El-Maarry, S. Fornasier, L. Giacomini, A.G. Gracia-Berná, S.F. Hviid, W.H. Ip, L. Jorda, H.U. Keller, J. Knollenberg, E. Kührt, F. La Forgia, I.L. Lai, Y. Liao, R. Marschall, M. Massironi, S. Mottola, M. Pajola, O. Poch, A. Pommerol, F. Preusker, F. Scholten, C.C. Su, J.S. Wu, J.-B. Vincent, H. Sierks, C. Barbieri, P.L. Lamy, R. Rodrigo, D. Koschny, H. Rickman, M.F. A'Hearn, M.A. Barucci, J.-L. Bertaux, I. Bertini, G. Cremonese, V. Da Deppo, S. Debei, M. de Cecco, M. Fulle, O. Groussin, P.J. Gutierrez, J.-R. Kramm, M. Küppers, L.M. Lara, M. Lazzarin, J.J. Lopez Moreno, F. Marzari, H. Michalik, G. Naletto, J. Agarwal, C. Güttler, N. Oklay, C. Tubiana, Astron. Astrophys. 583, A17 (2015a)

N. Thomas, H. Sierks, C. Barbieri, P.L. Lamy, R. Rodrigo, H. Rickman, D. Koschny, H.U. Keller, J. Agarwal, M.F.A. Hearn, F. Angrilli, A. Auger, M.A. Barucci, J. Kramm, E. Kührt, M. Küppers, F. La Forgia, Science (80-) 347, aaa0440 (2015b)

N. Thomas, M.R. El Maarry, P. Theologou, F. Preusker, F. Scholten, L. Jorda, S.F. Hviid, R. Marschall, E. Kührt, G. Naletto, H. Sierks, P.L. Lamy, R. Rodrigo, D. Koschny, B. Davidsson, M.A. Barucci, J.L. Bertaux, I. Bertini, D. Bodewits, G. Cremonese, V. Da Deppo, S. Debei, M. De Cecco, S. Fornasier, M. Fulle, O. Groussin, P.J. Gutièrrez, C. Güttler, W.H. Ip, H.U. Keller, J. Knollenberg, L.M. Lara, M. Lazzarin, J.J. Lòpez-Moreno, F. Marzari, C. Tubiana, J.B. Vincent, Planet. Space Sci. 164, 19-36 (2018)

D. Tirsch, K. Otto, S. Mottola, S. Hviid, R. Jaumann, L. Jorda, E. Kührt, K.-D. Matz, F. Preusker, in Eur. Planet. Sci. Congr. (2017). EPSC2017-739

J. Veverka, K. Klaasen, M. A’Hearn, M. Belton, D. Brownlee, S. Chesley, B. Clark, T. Economou, R. Farquhar, S.F. Green, O. Groussin, A. Harris, J. Kissel, J.Y. Li, K. Meech, J. Melosh, J. Richardson, P. Schultz, J. Silen, J. Sunshine, P. Thomas, S. Bhaskaran, D. Bodewits, B. Carcich, A. Cheuvront, T. Farnham, S. Sackett, D. Wellnitz, A. Wolf, Icarus 222, 424 (2013)

J.B. Vincent, D. Bodewits, S. Besse, H. Sierks, C. Barbieri, P. Lamy, R. Rodrigo, D. Koschny, H. Rickman, H.U. Keller, J. Agarwal, M.F. A’Hearn, A.T. Auger, M.A. Barucci, J.L. Bertaux, I. Bertini, C. Capanna, G. Cremonese, V. Da Deppo, B. Davidsson, S. Debei, M. De Cecco, M.R. El-Maarry, F. Ferri, S. Fornasier, M. Fulle, R. Gaskell, L. Giacomini, O. Groussin, A. Guilbert-Lepoutre, P. Gutierrez-Marques, P.J. Gutiérrez, C. Güttler, N. Hoekzema, S. Höfner, S.F. Hviid, W.H. Ip, L. Jorda, J. Knollenberg, G. Kovacs, R. Kramm, E. Kührt, M. Küppers, F. La Forgia, L.M. Lara, M. Lazzarin, V. Lee, C. Leyrat, Z.Y. Lin, J.J. Lopez Moreno, S. Lowry, S. Magrin, L. Maquet, S. Marchi, F. Marzari, M. Massironi, H. Michalik, R. Moissl, S. Mottola, G. Naletto, N. Oklay, M. Pajola, F. Preusker, F. Scholten, N. Thomas, I. Toth, C. Tubiana, Nature 523, 63 (2015a)

J.B. Vincent, N. Oklay, S. Marchi, S. Höfner, H. Sierks, Planet. Space Sci. 107, 53 (2015b)

J.-B. Vincent, M.F. A'Hearn, Z.-Y. Lin, M.R. El-Maarry, M. Pajola, H. Sierks, C. Barbieri, P.L. Lamy, R. Rodrigo, D. Koschny, H. Rickman, H.U. Keller, J. Agarwal, M.A. Barucci, J.-L. Bertaux, I. Bertini, S. Besse, D. Bodewits, G. Cremonese, V. Da Deppo, B. Davidsson, S. Debei, M. De Cecco, J. Deller, S. Fornasier, M. Fulle, A. Gicquel, O. Groussin, P.J. Gutiérrez, P. Gutiérrez-Marquez, C. Güttler, S. Höfner, M. Hofmann, S.F. Hviid, W.-H. Ip, L. Jorda, J. Knollenberg, G. Kovacs, J.-R. Kramm, E. Kührt, M. Küppers, L.M. Lara, M. Lazzarin, J.J. Lopez Moreno, F. Marzari, M. Massironi, S. Mottola, G. Naletto, N. Oklay, F. Preusker, F. Scholten, X. Shi, N. Thomas, I. Toth, C. Tubiana, Mon. Not. R. Astron. Soc. 462, S184 (2016) 
J.B. Vincent, S.F. Hviid, S. Mottola, E. Kuehrt, F. Preusker, F. Scholten, H.U. Keller, N. Oklay, D. de Niem, B. Davidsson, M. Fulle, M. Pajola, M. Hofmann, X. Hu, H. Rickman, Z.Y. Lin, C. Feller, A. Gicquel, S. Boudreault, H. Sierks, C. Barbieri, P.L. Lamy, R. Rodrigo, D. Koschny, M.F. A’Hearn, M.A. Barucci, J.L. Bertaux, I. Bertini, G. Cremonese, V. Da Deppo, S. Debei, M. De Cecco, J. Deller, S. Fornasier, O. Groussin, P.J. Gutiérrez, P. Gutiérrez-Marquez, C. Güttler, W.H. Ip, L. Jorda, J. Knollenberg, G. Kovacs, J.R. Kramm, M. Küppers, L.M. Lara, M. Lazzarin, J.J.L. Moreno, F. Marzari, G. Naletto, L. Penasa, X. Shi, N. Thomas, I. Toth, C. Tubiana, Mon. Not. R. Astron. Soc. 469, S329 (2017) 